\title{
Sorption of oils by a commercial non-woven polypropylene sorbent
}

\author{
Sorção de óleos por um sorvente não-tecido comercial de polipropilleno \\ Absorción de aceites por un absorbente comercial de polipropileno no tejido
}

Marcelo Zaro

ORCID: https://orcid.org/0000-0001-7716-380X Federal University of Rio Grande do Sul, Brazil E-mail: marcelo.zaro@ufrgs.br

Wendel Paulo Silvestre

ORCID: https://orcid.org/0000-0002-9376-6405 University of Caxias do Sul, Brazil E-mail: wpsilvestre@ucs.br

Jéssica Grapilha Fedrigo

ORCID: https://orcid.org/0000-0002-1332-2346 University of Caxias do Sul, Brazil E-mail: jgfedrig@ucs.br

Mara Zeni

ORCID: https://orcid.org/0000-0002-6917-5226 University of Caxias do Sul, Brazil E-mail:mzandrad@ucs.br

Camila Baldasso

ORCID: https://orcid.org/0000-0001-5763-8724 University of Caxias do Sul, Brazil E-mail: cbaldasso@ucs.br

\begin{abstract}
Non-woven polypropylene (PP) sorbents are materials that can be used in oil recovery following spills, which are interesting alternatives to remediate contaminated areas. This work aimed to characterize a non-woven sorbent made of PP. The physicochemical characteristics of the material, sorption capacity, kinetics, and adsorption isotherms were evaluated. The physicochemical study included the determination of thickness, density, thermal and chemical properties of the sorbent, and fiber morphology. Sorption tests were performed according to the standard method ASTM 726-12. The kinetic models of pseudo-first and pseudo-second order were tested. The fit of the experimental data to the adsorption isotherms of Langmuir, Freundlich, and Temkin was also carried out. The sorbates used in the tests were diesel, petroleum, and lubricant oil. The sorption capacity of the PP nonwoven blanket relative to diesel,

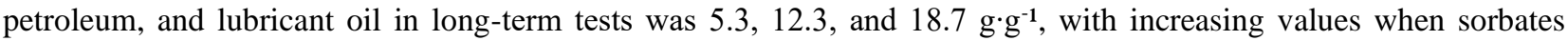
were more viscous. The results of the short and long-term tests did not show a statistical difference in the sorption capacity of the blanket. The kinetic study showed that the sorption of the three sorbates followed pseudo-second-order kinetics. The diesel oil presented a better fit to the Langmuir isotherm $\left(\mathrm{R}^{2}=0.998\right)$, whereas the petroleum presented an excellent fit to all three isotherms $\left(\mathrm{R}^{2}=0.996-0.999\right)$. Regarding sorbent reusability, the sorption capacity stabilized after the second cycle, and the samples whose sorbate removal was carried out by centrifugation have presented and maintained the highest sorption capacities.
\end{abstract}

Keywords: Adsorption isotherms; Kinetic study; Non-woven sorbent; Oil spill; Reusability.

\section{Resumo}

Absorventes de polipropileno (PP) não tecido são materiais que podem ser utilizados na recuperação de óleo após derramamentos, sendo alternativas interessantes para remediar áreas contaminadas. Este trabalho teve como objetivo caracterizar um sorvente não tecido de PP. Foram avaliadas as características físico-químicas do material, capacidade de sorção, cinética e isotermas de adsorção. O estudo físico-químico incluiu a determinação da espessura, densidade, propriedades térmicas e químicas do sorvente e morfologia da fibra. Os testes de sorção foram realizados de acordo com o método padrão ASTM 726-12. Os modelos cinéticos de pseudo-primeira e pseudo-segunda ordem foram testados. $\mathrm{O}$ ajuste dos dados experimentais às isotermas de adsorção de Langmuir, Freundlich e Temkin também foi realizado. Os sorbatos usados nos testes foram diesel, petróleo e óleo lubrificante. A capacidade de sorção da manta não tecida de PP em relação ao diesel, petróleo e óleo lubrificante em testes de longa duração foi de 5,3, 12,3 e 18,7 $\mathrm{g} \cdot \mathrm{g}^{-1}$, com valores crescentes quando os sorbatos eram mais viscosos. Os resultados dos testes de curto e longo prazo não mostraram diferença estatística na capacidade de sorção da manta. O estudo cinético mostrou que a sorção dos três sorbatos seguiu uma cinética de pseudo-segunda ordem. $\mathrm{O}$ óleo diesel apresentou melhor ajuste à isoterma de Langmuir $\left(R^{2}=0,998\right)$, enquanto o petróleo apresentou excelente ajuste às três isotermas $\left(R^{2}=0,996-0,999\right)$. Em 
relação à reutilização do sorvente, a capacidade de sorção se estabilizou após o segundo ciclo, e as amostras cuja remoção do sorbato foi realizada por centrifugação apresentaram e mantiveram as maiores capacidades de sorção.

Palavras-chave: Derramamento de petróleo; Estudo cinético; Isotermas de adsorção; Sorvente não-tecido; Reusabilidade.

\section{Resumen}

Los absorbentes de polipropileno (PP) no tejido son materiales que se pueden utilizar en la recuperación de petróleo después de derrames, que son alternativas interesantes para remediar áreas contaminadas. Este trabajo tuvo como objetivo caracterizar un sorbente no tejido de PP. Se evaluaron las características físicoquímicas del material, la capacidad de sorción, la cinética y las isotermas de adsorción. El estudio fisicoquímico incluyó la determinación del espesor, densidad, propiedades térmicas y químicas del sorbente y morfología de la fibra. Las pruebas de sorción se realizaron de acuerdo con el método estándar ASTM 726-12. Se probaron los modelos cinéticos de pseudo-primer y pseudo-segundo orden. También se llevó a cabo el ajuste de los datos experimentales a las isotermas de adsorción de Langmuir, Freundlich y Temkin. Los sorbatos utilizados en las pruebas fueron diesel, petróleo y aceite lubricante. La capacidad de sorción de la manta no tejida de PP en relación con el diesel, el petróleo y el aceite lubricante en las pruebas a largo plazo fue de 5,3, 12,3 y $18,7 \mathrm{~g} \cdot \mathrm{g}^{-1}$, con valores crecientes cuando los sorbatos eran más viscosos. Los resultados de las pruebas a corto y largo plazo no mostraron una diferencia estadística en la capacidad de sorción de la manta. El estudio cinético mostró que la sorción de los tres sorbatos siguió una cinética de pseudo segundo orden. El gasoil presentó un mejor ajuste a la isoterma de Langmuir $\left(\mathrm{R}^{2}=0,998\right)$, mientras que el petróleo presentó un ajuste excelente a las tres isotermas $\left(\mathrm{R}^{2}=0,996-0,999\right)$. En cuanto a la reutilización del sorbente, la capacidad de sorción se estabilizó después del segundo ciclo, y las muestras cuya remoción de sorbato se realizó por centrifugación han presentado y mantenido las mayores capacidades de sorción.

Palabras clave: Derrame de petróleo; Estudio cinético; Isotermas de adsorción; Sorbente no tejido; Reutilización.

\section{Introduction}

Oil spills are some of the most devastating environmental disasters, causing several lasting negative effects in both the fauna and flora, soil, water tables, and in the human populations near the spill. Although the enforcement of new environmental laws and procedures reduced the number of large-scale spills, these accidents still represent an important environmental problem (Rosa, Fraceto \& Moshini-Carlos, 2012; Wahi, Chua, Choong, Ngaini, \& Nourouzi, 2013).

Oils from both natural and synthetic origins are considered persistent pollutants. Beyond the deleterious effects on aquatic organisms and human beings, a major oil spill may very likely affect the regional economy by harming tourism and fishing operations (D’Andrea, Facro \& Reddy, 2013; Yang, Jin, Wei, He, Ji, Li \& Yu, 2009).

To counter the adverse effects of the spill and also recover the oil, fibrous polymeric sorbents are usually employed, such as non-woven polypropylene (PP) blankets (Callister \& Rethwisch, 2010; Shackelford, 2000). PP is a sorbent with nonpolar characteristics, which renders it a good sorbent of non-polar substances, such as petroleum derivates (Shaw, 1975).

The sorption process, which includes the phenomena of adsorption and absorption, depends on several physicochemical factors related to the properties of the sorbent and the medium in which the spilling occurred, such as $\mathrm{pH}$, temperature, oil concentration, and mixing conditions (Bansal, Arnim, Stegmaier \& Planck, 2011; Qi, Jia, Yang \& Liu, 2011; Simonovic et al., 2009; Singh, 2013). This process also depends on the kind of spilled oil, since the petroleum and refined products (naphtha, kerosene, diesel oil, and asphalt) may have quite different physicochemical properties (Companhia Ambiental do Estado de São Paulo, 2014; Dave \& Ghaly, 2011).

Wu, Wang, Wang, Dong, Zhao, and Jiang (2012) evaluated the sorption of several oils by PS fibers and films produced by electrospinning. The PS fibers presented a sorption capacity of 98.7, 67.1, 113.0, and $6.3 \mathrm{~g} \cdot \mathrm{g}^{-1} \mathrm{of}$ peanut, silicon, lubricant, and diesel oils, respectively. The porous film presented a sorption capacity of $112.3,81.4,131.6$, and $7.1 \mathrm{~g} \cdot \mathrm{g}^{-1} \mathrm{of}$ peanut, silicon, lubricant, and diesel oils, respectively.

Tanobe (2007) carried out the characterization of PU foams, which presented petroleum sorption capacities of 50, 45, 20, and $35 \mathrm{~g} \cdot \mathrm{g}^{-1}$, respectively. Teas, Kalligeros, Zanikos, Stournas, Lois, and Anastopoulos (2001) studied the sorption of petroleum by PP fibers. The PP fibers presented a sorption capacity of $4.5 \mathrm{~g} \cdot \mathrm{g}^{-1}$ in a seawater-oil system, whereas, in pure oil, the sorption capacity increased to $10.0 \mathrm{~g} \cdot \mathrm{g}^{-1}$. 
The determination of the efficiency of sorbent materials may be carried out by laboratory-scale assays that simulate spills and the variations of the factors that influence the sorption process. The sorbents may also be evaluated by their sorption capacity and the sorption-desorption kinetics (American Society of Testing and Materials, 2012; Sokker, El-Sawy, Hassan \& El-Anadouli, 2011; Tanobe, 2007).

This work aimed to evaluate the sorption capacity, sorption kinetics, and the performance parameters (reusability, buoyancy) of a non-woven PP blanket with petroleum, diesel, and lubricant oil as sorbates.

\section{Methodology}

\subsection{Materials characterization}

The sorbent used was a non-woven PP blanket, produced by melt-spinning and supplied by Ebios Tecnologia Sustentável (Caxias do Sul, Brazil), with a nominal thickness of $4 \mathrm{~mm}$. The sorbates used were weathered petroleum, supplied by Petrobras (Triunfo, Brazil), common diesel oil (Petrobras, Brazil), and SAE 85W-140 lubricant oil, supplied by Petronas Tutela $^{\circledR}$ (São Paulo, Brazil).

The physicochemical (thickness, density), spectral (Fourier-transform infrared spectroscopy - FTIR), and thermal (thermogravimetric analysis - TG/DTG) characteristics and the microstructure of the sorbent were determined; the viscosity and density of the sorbates were also measured.

Blanket thickness was measured using a Mitutoyo (Japan) MDC-SX digital micrometer, with a measuring range of 0$25 \mathrm{~mm}$ and a resolution of $1 \mu \mathrm{m}$. Density was measured using an Ohaus (USA) AS200 analytical balance, with a measuring range of 0-200 $\mathrm{g}$ and a resolution of $0.1 \mathrm{mg}$.

Blanket and fiber structure was evaluated by scanning electron microscopy (SEM), using a Shimadzu (Japan) SSX500 microscope, with an acceleration voltage of $15 \mathrm{kV}$. The samples were previously covered with a thin layer of gold. Samples of the cross-section of the fibers were analyzed by freezing the material with liquid nitrogen $\left(-196{ }^{\circ} \mathrm{C}\right)$, followed by fracturing.

The spectral characterization of the sorbent was carried out by FTIR, using a KBr cell and a Nicolet CM-2500d infrared spectrophotometer, with a range of $400-4000 \mathrm{~cm}^{-1}$ and a resolution of $0.25 \mathrm{~cm}^{-1}$.

The thermal properties of the blanket were determined by TG/DTG and DSC. The TG analysis used a Shimadzu (Japan) TA-60WS thermobalance with nitrogen atmosphere from 25 up to $800{ }^{\circ} \mathrm{C}$ at $20{ }^{\circ} \mathrm{C} \cdot \mathrm{min}^{-1}$; the software equipment generated the DTG curve from TG data. Three samples (10 mg) were used.

Sorbate density was measured using an Incoterm (Brazil) Baumé densimeter. The viscosity of the sorbates was determined using a Brookfield LV viscosimeter, operating at $100 \mathrm{rpm}$. S63 and S61 spindles were used for the measurement of the viscosity of lubricant oil and petroleum, respectively. Diesel oil viscosity was measured using a Quimis (Brazil) Q860A analogic viscosimeter with an $n^{\circ} 1$ spindle.

The petroleum underwent a simulated weathering process. It consisted of keeping a petroleum layer with $1.5 \mathrm{~cm}$ of thickness in Petri dishes for 1, 3, 6, 9, 24, 48, 72, 172, 196, 220, and $345 \mathrm{~h}$ at $20 \pm 4{ }^{\circ} \mathrm{C}$ (Johnson, Manjrekar \& Halligan, 1973). By plotting the obtained data and the evaluation of the coefficient of determination $\left(\mathrm{R}^{2}\right)$ of the mass loss curve, a weathering time for the petroleum samples was determined. The samples underwent this weathering time to simulate the real environmental conditions and also to standardize the analysis.

\subsection{Sorption tests}

The sorption tests were carried out according to the ASTM F726-12 standard, both for the short and long term (ASTM, 2012). Test samples were cut in 13 x $13 \mathrm{~cm}\left(169 \mathrm{~cm}^{2}\right)$ pieces and kept in contact with the sorbates at $23 \pm 4{ }^{\circ} \mathrm{C}$ and 
$70 \pm 20 \%$ RH. All test samples were previously weighted using an analytical balance and put in containers with sufficient sorbent for the test samples to float freely. In the short-term test, the samples were in contact with the sorbates for $15.0 \pm 0.3 \mathrm{~min}$, whereas in the long-term test, they were in contact for $24.0 \pm 0.5 \mathrm{~h}$.

The samples were removed from the sorbate-containing vessels and kept for $30 \pm 2 \mathrm{~s}$ in a vertical position to remove the oil in the surface, posteriorly the samples were weighted. The sorption capacity was determined by using equation 1.

$$
S C=\frac{w_{f}-w_{i}}{w_{i}}
$$

Where SC is the sorption capacity of the sample (in grams of sorbate per gram of polymer $-\mathrm{g}^{\cdot \mathrm{g}^{-1}}$ ), $\mathrm{w}_{\mathrm{i}}$ is the initial weight of the polymer sample $(\mathrm{g})$, and $\mathrm{w}_{\mathrm{f}}$ is the sample weight at the end of the test $(\mathrm{g})$.

Along with petroleum, diesel, and lubricant oil sorption tests, water uptake tests were also carried to verify the water uptake by the PP blanket. The tests were carried out at the same conditions as the oil sorption tests in two conditions: static test, in which the samples were kept still, and dynamic tests, in which the sample was shaken at $150 \mathrm{rpm}$ and amplitude of movement of $15 \mathrm{~cm}$.

\subsection{Kinetic study}

A sorption kinetic study for the PP blanket was carried out using the three oils. The tests were carried out in a biphasic (water/oil) static medium. Samples of the PP blanket with the dimensions of 1.5 x $1.5 \mathrm{~cm}$ were put in $150 \mathrm{~mL}$ Becker cups containing $100 \mathrm{~g}$ of water and 1,3, and $5 \mathrm{~g}$ of the oils. These quantities were chosen to represent an oil removal capacity of the sorbent in the range of $10-100 \%$, to allow for a better evaluation of the effect of the sorbent concentration on the sorption capacity of the sorbent as a function of time $\left(\mathrm{q}_{\mathrm{t}}\right)$ and in equilibrium $\left(\mathrm{q}_{\mathrm{e}}\right)$.

The tests were carried out in triplicates at $23 \pm 3{ }^{\circ} \mathrm{C}$. The sorption times of $0.25,0.50,1.00,3.00,5.00,10.00,20.00$, 30.00, and 60.00 min were evaluated. The obtained data were adjusted according to the sorption kinetics of each sorbate. The amount of water sorbed by the blanket was determined by extraction with n-hexane, based on the procedure described in the Standard Methods for the Examination of Water and Wastewater (2012) for oils and greases.

The removal percentages of the sorbates in the equilibrium $\left(\mathrm{R}_{\mathrm{e}}\right)$ and at different times $\left(\mathrm{R}_{\mathrm{t}}\right)$ were calculated by equations 2 and 3 .

$$
\begin{aligned}
& R_{e}=\frac{100 \times\left(C_{0}-C_{e}\right)}{C_{0}} \\
& R_{t}=\frac{100 \times\left(C_{0}-C_{t}\right)}{C_{0}}
\end{aligned}
$$

Where $\mathrm{C}_{0}$ is the starting concentration of the sorbate $\left(\mathrm{g} \cdot \mathrm{L}^{-1}\right), \mathrm{C}_{\mathrm{e}}$ is the concentration of the sorbate in the equilibrium $\left(\mathrm{g} \cdot \mathrm{L}^{-1}\right)$, and $\mathrm{C}_{\mathrm{t}}$ is the concentration of the sorbate $\left(\mathrm{g} \cdot \mathrm{L}^{-1}\right)$ in the time ' $\mathrm{t}$ '. The total amount of sorbate sorbed by the sorbent was calculated using equations 4 and 5 .

$$
\begin{aligned}
& q_{e}=\frac{V \times\left(C_{0}-C_{e}\right)}{m} \\
& q_{t}=\frac{V \times\left(C_{0}-C_{t}\right)}{m}
\end{aligned}
$$


Where $\mathrm{q}_{\mathrm{e}}$ is the sorption capacity of the sorbent in the equilibrium $\left(\mathrm{g} \cdot \mathrm{g}^{-1}\right)$, qt is the sorption capacity in the time ' $\mathrm{t}$ ', $\mathrm{V}$ is the volume of the solution $(\mathrm{L}), \mathrm{m}$ is the mass of the dry sorbent $(\mathrm{g}) ; \mathrm{C}_{0}, \mathrm{C}_{\mathrm{e}}$, and $\mathrm{C}_{\mathrm{t}}$ are the concentrations of sorbate at the start, in the equilibrium, and at the time ' $\mathrm{t}$ ', respectively $\left(\mathrm{g} \cdot \mathrm{L}^{-1}\right)$.

The kinetic linearized models of pseudo-first (equation 6) and pseudo-second order (equation 7) were used to determine the sorption parameters and the sorption capacity of the sorbent in the equilibrium.

$$
\begin{gathered}
\ln \left(q_{e}-q_{t}\right)=\ln \left(q_{e}\right)-\frac{k_{1}}{2.303} \times t \\
\frac{t}{q_{t}}=\frac{1}{k_{2} \times q_{e}{ }^{2}}+\frac{1}{q_{e}} \times t
\end{gathered}
$$

Where $\mathrm{k}_{1}\left(\mathrm{~min}^{-1}\right)$ and $\mathrm{k}_{2}\left(\mathrm{~g} \cdot \mathrm{g}^{-1} \cdot \mathrm{min}^{-1}\right)$ are the kinetic rate constants of the studied models.

\subsection{Adsorption isotherms}

The fitting of sorption data on the isotherm models of Langmuir, Freundlich, and Temkin was evaluated to verify the physicochemical process and interactions that occurred between the diesel oil and petroleum and the PP blanket. The adsorption isotherms for lubricant oil were not evaluated due to its high viscosity. The linearized form of the Langmuir isotherm model is presented in equation 8 .

$$
\frac{C_{e}}{q_{e}}=\left(\frac{1}{K_{L} \times q_{0}}\right)+\left(\frac{1}{q_{0}}\right) \times C_{e}
$$

Where $\mathrm{C}_{\mathrm{e}}$ is the concentration of sorbate in the equilibrium $\left(\mathrm{g} \cdot \mathrm{L}^{-1}\right), \mathrm{q}_{\mathrm{e}}$ is the sorption capacity of the sorbent relative to the sorbate $\left(\mathrm{g} \cdot \mathrm{g}^{-1}\right)$, and $\mathrm{K}_{\mathrm{L}}$ is the Langmuir constant $\left(\mathrm{L} \cdot \mathrm{g}^{-1}\right)$ of the system.

The linearized form of the Freundlich isotherm model is presented in equation 9.

$$
\ln \left(q_{e}\right)=\ln \left(K_{f}\right)+\left(\frac{1}{n}\right) \times \ln \left(C_{e}\right)
$$

Where $\mathrm{q}_{\mathrm{e}}$ is the sorption capacity of the sorbent relative to the sorbate $\left(g \cdot \mathrm{g}^{-1}\right)$, ' $1 / \mathrm{n}$ ' is the heterogeneity factor, and $\mathrm{K}_{\mathrm{f}}$

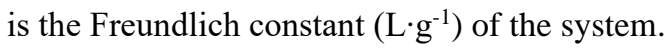

The Temkin isotherm model is presented in equation 10 .

$$
q_{e}=\frac{R T}{b} \times\left[\ln (A)+\ln \left(C_{e}\right)\right]
$$

Where $\mathrm{q}_{\mathrm{e}}$ is the sorption capacity of the sorbent relative to the sorbate $\left(\mathrm{g} \cdot \mathrm{g}^{-1}\right), \mathrm{R}$ is the gas constant $\left(8.314 \mathrm{~J} \cdot \mathrm{mol}^{-1} \cdot \mathrm{K}^{-1}\right)$, $\mathrm{T}$ is the temperature $(\mathrm{K})$ of the system, $\mathrm{A}$ is the equilibrium binding constant $\left(\mathrm{L} \cdot \mathrm{mol}^{-1}\right), \mathrm{C}_{\mathrm{e}}$ is the concentration of the sorbate in the equilibrium $\left(\mathrm{g} \cdot \mathrm{L}^{-1}\right)$, and $\mathrm{b}$ is a constant related to adsorption heat $\left(\mathrm{J} \cdot \mathrm{mol}^{-1} \cdot \mathrm{g}^{-1}\right)$.

The fitting parameters for all three linearized isotherms were evaluated relative to the correlation $\left(\mathrm{R}^{2}\right)$ coefficient to observe which model presented the best match with the empirical results. The reversibility/irreversibility of the sorption process was evaluated by the value of the dimensionless constant RL, calculated according to equation 11. 


$$
R_{L}=\frac{1}{\left(1+K_{L} \times C_{0}\right)}
$$

Where $\mathrm{R}_{\mathrm{L}}$ is the dimensionless separation factor, $\mathrm{C}_{0}$ is the starting sorbate concentration $\left(\mathrm{g} \cdot \mathrm{L}^{-1}\right)$, and $\mathrm{K}_{\mathrm{L}}$ is the

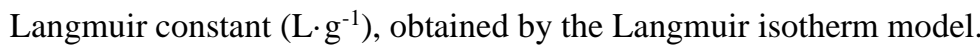

According to Ahmad, Sumathi, and Hameed (2005) and Ayawei, Ebelegi, and Wankasi (2017), $\mathrm{R}_{\mathrm{L}}=0$ indicates an irreversible process; $\mathrm{R}_{\mathrm{L}}=1.0$ indicates linear sorption; $\mathrm{R}_{\mathrm{L}}$ values in the range of 0.0-1.0 indicate a favorable adsorption process; $\mathrm{R}_{\mathrm{L}}$ values greater than 1.0 indicate a non-favorable adsorption process.

\subsection{Flotation tests}

The flotation tests were based on the ASTM F726 standard (ASTM, 2012). Test bodies with the dimensions of $6 \times 6$ $\mathrm{cm}$ were prepared, weighted, and put in a four-liter vessel, with $2 \mathrm{~L}$ of water. The samples were put in the vessel, and the water was mixed using a bench-scale mixer with reciprocal movement. The samples were shaken for $15 \mathrm{~min}$ at $150 \mathrm{rpm}$ and amplitude of movement of $15 \mathrm{~cm}$. Posteriorly, the system was kept still for $2 \mathrm{~min}$. Then, both water and the sorbent were evaluated. If the sorbent was not floating after the test, it was considered reproved.

\subsection{Reusability tests}

The experimental procedure followed the ASTM F726-12 standard (ASTM, 2012). Three adsorbate removal procedures were employed: mechanical pressing using a hydraulic press, mechanical pressing using a roller press, and centrifugation.

The sorbate removal by mechanical pressing was carried out using a Schulz (São Paulo, Brazil) PHS mechanical press, with a capacity of $15 \mathrm{t}$; the applied pressure was $0.7 \mathrm{kgf} \cdot \mathrm{cm}^{-2}(68.65 \mathrm{kPa})$ for $15 \pm 2 \mathrm{~s}$. The removal by roller pressing used an Eletron (Caxias do Sul, Brazil) roller pressing, with roller dimensions of $15 \mathrm{~cm}$ length and $31 \mathrm{~cm}$ of diameter. The distance between rollers was $2 \mathrm{~mm}$ (half of the blanket nominal thickness), and the roller speed was $10 \mathrm{~cm} \cdot \mathrm{s}^{-1}$. The removal by centrifugation used a Mueller (Timbó, Brazil) common centrifuge for $3 \mathrm{~min}$ at $1800 \mathrm{rpm}$.

The tests were carried out in triplicates using lubricant oil as the sorbate. This sorbate was chosen due to its high viscosity (Table 1), which may difficult sorbate removal from sorbent structure (Rana, Pramanik, Martin, De Wit \& Mishra, 2019). The blanket samples were saturated, the sorbate removed, and the sorbent was weighted. The cycles were repeated six times, and the sorbed mass of diesel in the samples was calculated using Equation 1; the sorbate removal efficiency was calculated according to Equation 12.

$$
\mathrm{OR}_{\mathrm{x}}(\%)=100 \times\left(\frac{\left(\mathrm{O}_{\mathrm{STx}}-\mathrm{S}_{\mathrm{Ox}}\right)-\mathrm{O}_{\mathrm{Nx}}}{\left(\mathrm{O}_{\mathrm{STX}}-\mathrm{S}_{\mathrm{OX}}\right)}\right)
$$

Where $\mathrm{OR}_{\mathrm{x}}$ is the oil removal efficiency in the cycle ' $\mathrm{x}$ '; $\mathrm{O}_{\mathrm{STx}}$ is the adsorbent mass after saturation in the cycle ' $\mathrm{x}$ ', $\mathrm{S}_{\mathrm{Ox}}$ is the adsorbent mass before sorption in the cycle ' $\mathrm{x}$ ', and $\mathrm{O}_{\mathrm{Nx}}$ is the mass of sorbate already present in the sorbent before cycle ' $x$ '.

\subsection{Experimental design and statistical analysis}

Blanket thickness and density, as well as the density and viscosity of the oils, were evaluated with six replicates. All oil sorption tests (sorption and desorption) were carried out in triplicates and, if the sorption capacity replicates presented a deviation higher than $15 \%$, the tests were carried out again with new samples. The data underwent analysis of variance 
(ANOVA), using the Statistica $12^{\circledR}$ software (Statsoft, USA).

\section{Results and Discussion}

\subsection{Materials characterization}

\subsubsection{PP blanket sorbent}

According to the performed tests, the average thickness and density of the PP blanket were $2.83 \pm 0.54 \mathrm{~mm}$ and $0.10 \pm 0.04 \mathrm{~g} \cdot \mathrm{cm}^{-3}$, respectively. Relative to the average thickness, the measured value was $26.2 \%$ smaller than the nominal one. It was also possible to observe that the PP blanket was not uniform regarding its thickness and density depending on the sample collected. Figure 1 presents the thermogravimetric analysis (TG) and the differential thermogravimetric curve (DTG) of the PP blanket.

In section ' $a b$ ' it was possible to verify that the sample remained stable. The dot ' $b$ ' indicated the onset of the thermal degradation of the polymer, which was $321.79{ }^{\circ} \mathrm{C}$. At the dot ' $\mathrm{c}$ ', the maximum mass loss occurred at the temperature of $434.62{ }^{\circ} \mathrm{C}$. The dot ' $\mathrm{d}$ ' indicated the offset of the DTG curve, in which most of the thermal degradation of the material ended, at $454.29^{\circ} \mathrm{C}$. The plateau 'de' characterized the thermal stability of possible remaining material, such as inorganics.

Figure 1 - TG/DTG analysis of the PP blanket.

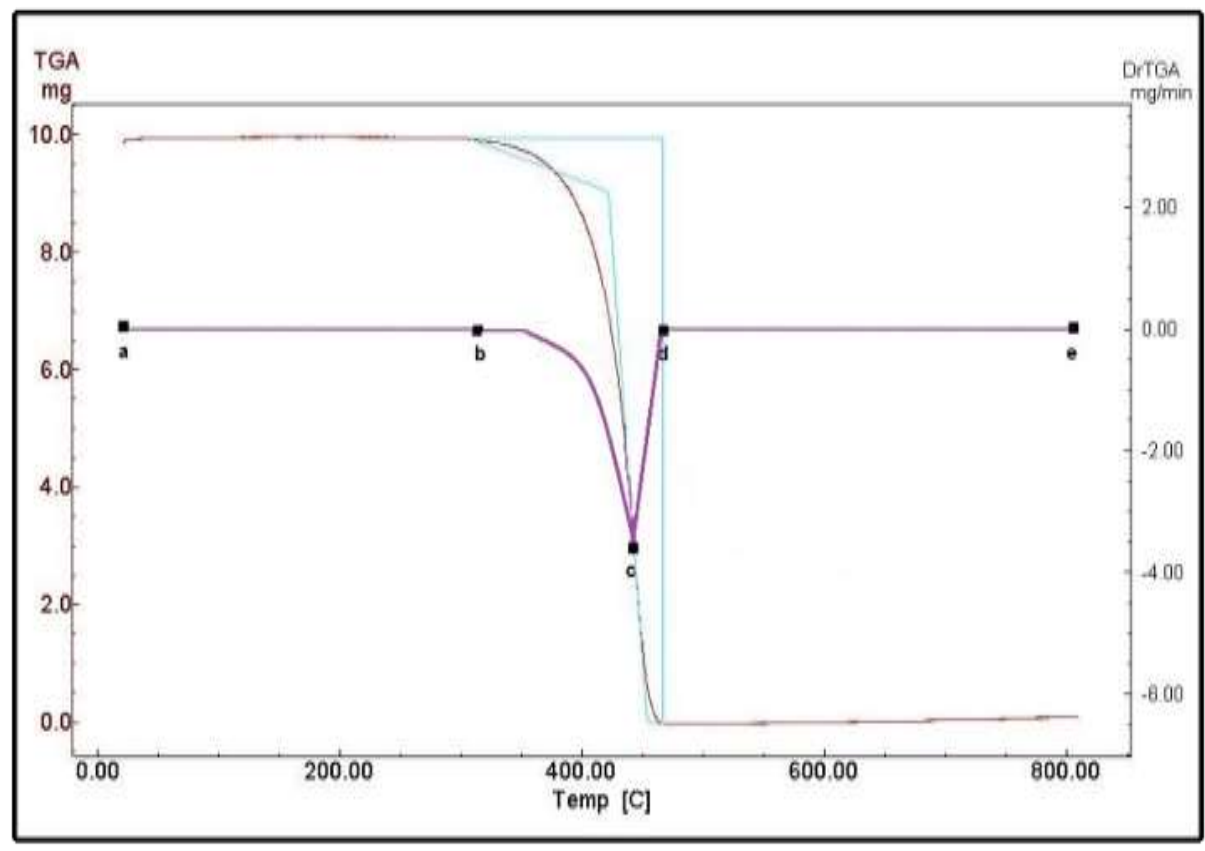

Source: Authors (2021).

By the TG/DTG analysis, it can be seen that the maximum mass loss occurred at $434.62{ }^{\circ} \mathrm{C}$; this value is similar to the ones reported by Rosa (2007) and Líbano, Visconte, and Pacheco (2012). At $800{ }^{\circ} \mathrm{C}$, about all of the blanket was degraded, with a residual relative mass of only $0.01 \%$. indicating a complete thermal degradation of the material.

Figure 2 presents the FTIR spectrum of the PP blanket. 
Figure 2 - FTIR spectrum of the PP blanket.

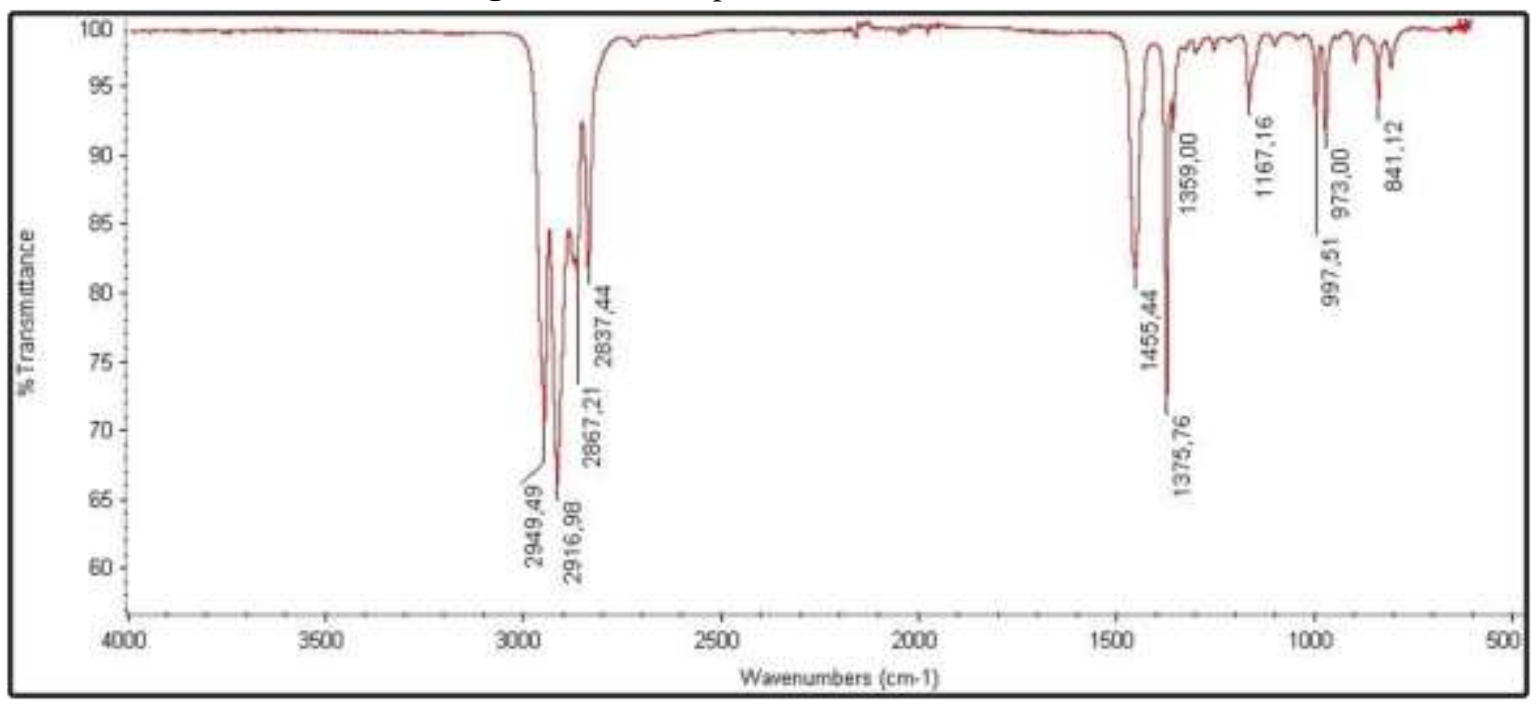

Source: Authors (2021).

The peaks at $2949 \mathrm{~cm}^{-1}$ (stretching of $\mathrm{CH}$ and $\left.\mathrm{CH}_{3}\right), 2917 \mathrm{~cm}^{-1}$ (stretching of $\mathrm{CH}$ and $\left.\mathrm{CH}_{2}\right), 1455 \mathrm{~cm}^{-1}\left(\mathrm{CH}_{2}\right.$ bending), and $1375 \mathrm{~cm}^{-1}$ ( $\mathrm{CH}$ bending) are characteristic of PP and show the presence of $\mathrm{CH}, \mathrm{CH}_{2}$, and $\mathrm{CH}_{3}$ moieties (Qi et al., 2011; Rengazamy, Das \& Karan, 2011; Trombetta, 2010). From TG/DTG, and FTIR analyses, it can be seen that the feedstock used in the production of the sorbent was an isotactic homopolymer PP. Figure 3 presents the MEV micrographs of the blanket samples.

Figure 3 - MEV micrographs of the PP blanket samples.

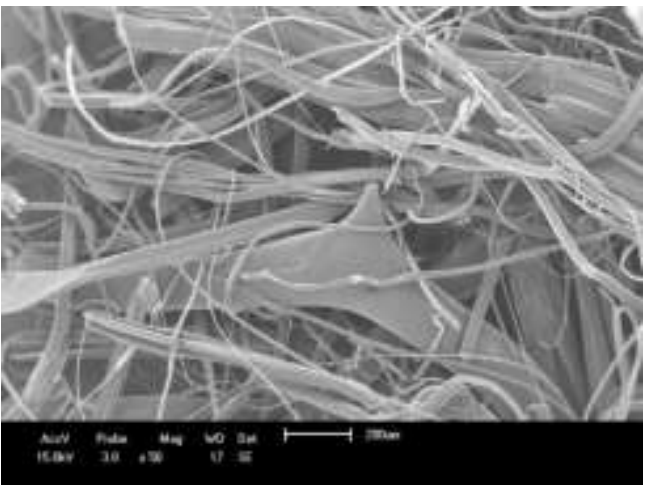

(A)

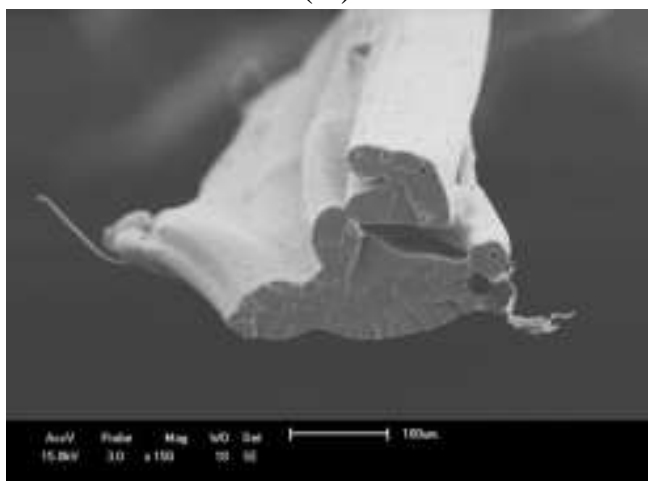

(C)

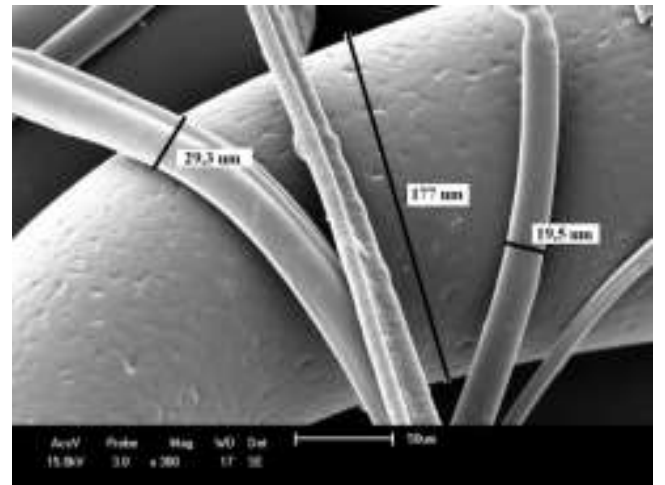

(B)

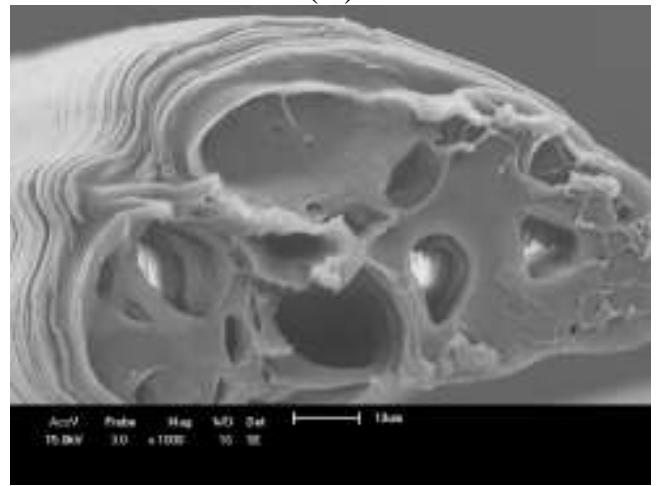

(D)

A - 50x magnification; B - 300x magnification and measurement of the approximate diameter of the fibers; C - 150x magnification of the cross-section of a fiber; D - 1000x magnification of the cross-section of a fiber. Source: Authors (2021). 
The MEV micrographs of the blanket samples (Figure 3A) show a disordered entanglement of the polymeric fibers, as well as individual fibers and also aggregates. The overall distribution of the fibers was random, indicating an amorphous material; amorphous materials tend to have higher sorption capacities and rates than crystalline materials (Nurhadi \& Roos, 2016). There were differences among the fiber diameters (Figure 3B), which ranged about an order of magnitude (19.5 to $177.0 \mu \mathrm{m})$.

According to Wei, Mather, Fotheringham, and Yang (2003), the differences in fiber size/diameter are a result of the manufacturing process and may influence the sorption capacity of the polymer. The same authors compared five kinds of nonwoven sorption blankets with their density, porosity, thickness, and fiber size. The more porous blankets presented a higher oil sorption rate, but the overall retention capacity was smaller than the blankets with less porosity. The melt-blown blankets have presented good oil sorptions probably due to the smaller fiber diameter, which results in higher surface areas, which favors sorbate-sorbent interaction. The individual fiber morphology varies from one to another, but the overall fiber aspect was irregular. The more irregular is the surface of a sorbent, the greater is its surface area, which means more active sites for sorbate deposition and absorption (Singh, 2013; Wu et al., 2012).

The micrographs of the cross-section of the fibers (Figures 3C and 3D) showed that the fibers present both solid and hollow sections. The hollow sections may be sites of sorbate deposition if there is any connection between the hollow cavity of the fiber and the external medium (i.e., defects or openings in the fiber).

Despite the presence of hollow parts, the fibers characterized in the present work cannot be characterized as porous, such as the ones produced by Lin, Shang, Ding, Yang, Yu, and Al-Deyab (2012). They highlight the importance of fiber porosity in the sorption process because this structure may enhance some physicochemical interactions and phenomena, such as capillarity. The same authors, comparing the sorption performance of nanoporous polystyrene (PS) fibers with conventional PP fibers, verified an increase in the sorption capacity of 3-4 times of the PS fibers. In this case, the increase of the sorption capacity was associated with a higher fiber porosity and also with a smaller fiber diameter of the PS fibers (2.37 $\mu \mathrm{m})$ when compared to the conventional PP fibers $(20.00 \mu \mathrm{m})$.

\subsubsection{Characterization of the oils}

Considering the chemical composition of the oils tested, petroleum is characterized as a mixture of several hydrocarbons ranging from C5 up to oligomers in the range of hundreds of Daltons; there is also the presence of aromatic molecules and polycyclic aromatic hydrocarbons in variable amounts. Due to the high number of substances that compose petroleum, it is difficult to determine its exact composition. However, it is composed mostly of hydrocarbons ranging from C10 to C60, and a semisolid fraction generally called 'asphalt' (Bayona, Domínguez, and Albaigés, 2015).

Diesel oil (Diesel fuel) is an intermediate fraction of petroleum (distillation window between 200-350 ${ }^{\circ} \mathrm{C}$ ) composed mainly of aliphatic C10-C20 hydrocarbons (75\%) and aromatic hydrocarbons such as benzene and styrene (about 25\%); small amounts of sulfur may be present depending on the oil origin and previous desulfurization steps (Bayona et al., 2015; Jahnson, 2013).

The SAE 85W-140 oil and most lubricant oils are composed mainly of petroleum hydrocarbon distillates (80-90\%) generally heavier than the diesel oil fraction (>C15) and additives (10-20\%) used to provide specific physicochemical characteristics to the oil, such as higher viscosity and lower vapor pressure, especially when used in high-temperature applications (Wexler, 2005).

The petroleum sample underwent a weathering test, whose results are presented in Figure 4. After 170 h, about 20 wt.\% of the initial mass loss of petroleum sample was lost, mostly due to the volatilization of some of its components. Between 170 and $345 \mathrm{~h}$, the mass loss was from 20.5 to $21.8 \mathrm{wt}$ \% (1.3 wt.\%). These results are similar to the ones observed by John son 
et al. (1973). After $48 \mathrm{~h}$, these authors reported an overall mass loss of $16.5 \mathrm{wt} . \%$, quite similar to the values observed in this work (16.9 wt.\%), and an average mass loss of $22.5 \mathrm{wt} \%$ after $190 \mathrm{~h}$. From this time on, the authors considered the mass loss as negligible; after $196 \mathrm{~h}$ of weathering, there was a mass loss of $20.7 \mathrm{wt} \%$ of the petroleum sample, with little further loss after this time. The correlation of the experimental data with a quadratic fitting presented a determination coefficient $\left(\mathrm{R}^{2}\right)$ of 0.990 .

Figure 4 - Results of the weathering test of the petroleum sample as a function of time.

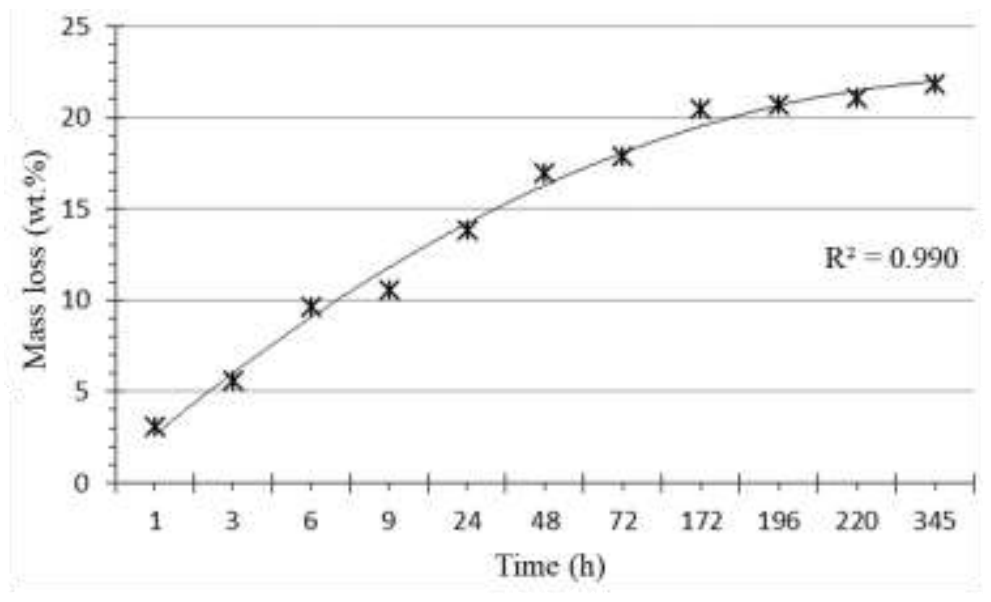

Source: Authors (2021).

Souza and Triguis (2005) studied the weathering process of petroleum and verified a reduction in the content of alkanes, phenanthrenes, and methyl-dibenzothiophenes, mainly due to evaporation. The authors also reported that after four days of weathering the loss of alkanes was $66 \%$, reaching $81 \%$ after 28 days.

Aghajanloo and Pirooz (2011) simulated the weathering process of petroleum using scattering, evaporation, vertical dispersion, dissolution, and emulsification methods; the results were correlated to experimental data. According to the simulations, after 5 days of weathering, $35 \%$ of the petroleum mass was lost due to evaporation, $10 \%$ dissolved in water, and $55 \%$ remained in the water-air interface. According to the authors, these results may suffer changes due to environmental conditions.

Table 1 presents the data on the dynamic viscosity and density of the sorbates studied in this work. The obtained values were similar to the ones reported by Wei et al. (2003), Abdullah, Rahmah, and Man (2010), Hasan, Ghannam, and Esmail (2010), Qi et al. (2011), Canciam (2012), and Peng, Lan, Guo, Yang, and Dang (2013).

Table 1 - Dynamic viscosity and density of the studied sorbates.

\begin{tabular}{|c|c|c|c|}
\hline Sorbate & Dynamic viscosity $(\mathrm{Pa} \cdot \mathrm{s})$ & Density $\left(\mathrm{kg} \cdot \mathrm{m}^{-3}\right)$ & Kinematic viscosity $\left(\mathrm{m}^{2} \cdot \mathrm{s}\right)$ \\
\hline Diesel oil & $0.005\left(22.0^{\circ} \mathrm{C}\right)$ & 832 & $6.00 \cdot 10^{-6}$ \\
\hline Lubricant SAE $85 \mathrm{~W}-140$ & $0.931\left(24.0^{\circ} \mathrm{C}\right)$ & 901 & $1.03 \cdot 10^{-3}$ \\
\hline Crude petroleum & $0.018\left(19.7^{\circ} \mathrm{C}\right)$ & 830 & $2.16 \cdot 10^{-5}$ \\
\hline Weathered petroleum & $0.095\left(20.0^{\circ} \mathrm{C}\right)$ & 850 & $1.12 \cdot 10^{-4}$ \\
\hline Water & $0.001\left(20.0^{\circ} \mathrm{C}\right)$ & 996 & $1.00 \cdot 10^{-6}$ \\
\hline
\end{tabular}

Source: Authors (2021).

Relative to the viscosity of the sorbates studied in the present work, it ranged from $0.001 \mathrm{~Pa} \cdot \mathrm{s}$ (water) to $0.931 \mathrm{~Pa} \cdot \mathrm{s}$ (lubricant oil); it was also noteworthy the difference between the viscosity of the crude and weathered petroleum, which increased more than five times. 
The sorbate viscosity has an important effect on the sorption kinetics and influences the sorbent/sorbate interface. This physicochemical parameter influences the diffusion/dispersion rate of the sorbate and also the thickness of the expanding oil stain (CETESB, 2014; International Marine Organization, 2005). Wei et al. (2003) observed that an increase in viscosity induced an increase in petroleum sorption capacity of non-woven PP sorbents. On the other hand, it hindered the capillary effect of the oil to penetrate the smaller pores of the sorbent structure.

Lin et al. (2012) cited that sorbate viscosity has an important role regarding the sorption rates of several sorbents. The authors reported that, after $5 \mathrm{~min}$ of contact, only $3 \mathrm{~g}$ of lubricant oil were sorbed by a nanoporous PS fiber, whereas, at the same time, approximately 76 and $80 \mathrm{~g}$ of soybean and sunflower oils, which are less viscous, were sorbed by the PS fibers. Teas et al. (2001), working with petroleum, light cycle oil (LCO), and light gas oil (LGO), reported a similar trend of increase of sorption capacity of the sorbent relative to sorbate viscosity, citing the decrease of the capillary effect as a possible cause for this behavior.

Regarding the density of the sorbates, its main effect is on sorbate buoyancy since densities higher than water will cause the sorbate (or its heavier fractions) to sink and settle at the seafloor. Therefore, for a floating sorbent, only the lighter (less dense) fractions of the sorbate will be sorbed; the heavier fractions will sink, whereas the much lighter ones will tend to evaporate, as can be observed in the petroleum weathering tests. However, it is important to consider the influence of temperature in both evaporation rate and water/sorbate density (Lin et al., 2012; Wei et al., 2003).

\subsection{Sorption tests}

\subsubsection{Oil sorption tests}

Short- and long-term tests were carried out with the three sorbates (diesel, lubricant oil, and weathered petroleum). The sorption capacity of the blanket relative to each sorbate for each test is presented in Figure 5.

Figure 5 - Long- and short-term sorption capacity of the PP blanket relative to each sorbate.

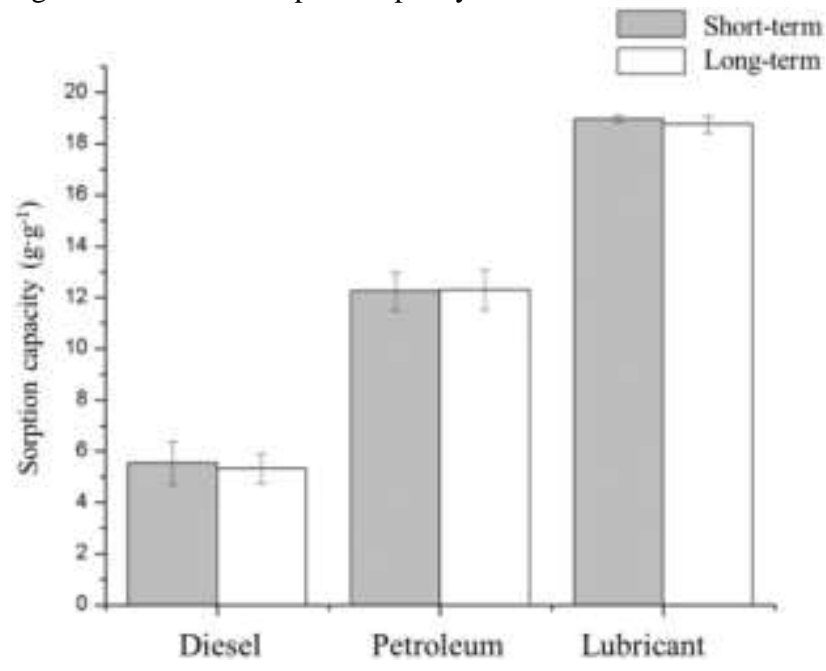

Source: Authors (2021).

The blanket sorption capacity of diesel was $5.53 \mathrm{~g} \cdot \mathrm{g}^{-1}$ in the short-term test, whereas it decreased to $5.38 \mathrm{~g} \cdot \mathrm{g}^{-1}$ in the long-term test, however, there was no statistical difference between the test time. For the lubricant oil, the short-term test indicated a sorption capacity of $18.96 \mathrm{~g} \cdot \mathrm{g}^{-1}$, whereas for the long-term test it also decreased to $18.32 \mathrm{~g} \cdot \mathrm{g}^{-1}$. As the diesel oil, there was no statistical difference between the long- and short-term lubricant oil sorption capacities. Lim and Huang (2007) 
characterized PP fibers relative to their sorption capacity of diesel oil, engine oil, and hydraulic oil. The results reported by these authors were similar to the ones obtained in the present work relative to the diesel oil, whose sorption capacity varied from 3.0 and $8.2 \mathrm{~g} \cdot \mathrm{g}^{-1}$, depending only on the specific mass of the sorbent $\left(0.10-0.22 \mathrm{~g} \cdot \mathrm{cm}^{-3}\right)$. These differences may also be the result of the difference in the dynamic viscosity of the sorbates $(0.005 \mathrm{~Pa} \cdot \mathrm{s}$ for the diesel and $0.931 \mathrm{~Pa} \cdot \mathrm{s}$ for the lubricant oil, respectively - Table 2).

The petroleum sorption capacity was between the sorption of diesel and the lubricant oil. In the short-time test, it was $12.24 \mathrm{~g} \cdot \mathrm{g}^{-1}$, whereas in the long-term test it increased slightly to $12.36 \mathrm{~g} \cdot \mathrm{g}^{-1}$. According to Figure 6 , the long- and short-term sorption capacities of the PP blanket have not differed statistically for any of the oils. The obtained results were similar to the ones reported by Teas et al. (2001) and Wei et al. (2003), who studied the sorption of crude and weathered petroleum employing non-woven PP sorbents. The reported petroleum sorption capacities were around $10.00 \mathrm{~g} \cdot \mathrm{g}^{-1}$, both for crude and weathered petroleum samples.

The tests also showed that, the more viscous the sorbate, the higher the blanket sorption capacity. Wei et al. (2003) observed that an increase of sorbate viscosity from 0.01 to $0.05 \mathrm{~Pa} \cdot \mathrm{s}$ enhanced the petroleum sorption by non-woven PP blankets produced by the melt-blown process. However, with a sorbate with a viscosity of $0.63 \mathrm{~Pa} \cdot \mathrm{s}$, the overall sorption capacity was smaller. The authors attributed this behavior to a smaller diameter of the blanket fibers; the higher sorbate viscosity hindered its penetration by capillary action through the smaller pores and imperfections of the sorbent.

By verifying the results of the long-term test, it was possible to infer that the blanket was saturated after 15 min of contact with the sorbates, since the sorption capacities determined in both the short- and long-term tests were quite similar, not even differing statistically by the ANOVA.

\subsubsection{Water uptake tests}

The water uptake by the PP blanket was also evaluated. The results are presented in Figure 6.

Figure 6 - Water uptake of the PP blanket in the static and dynamic tests.

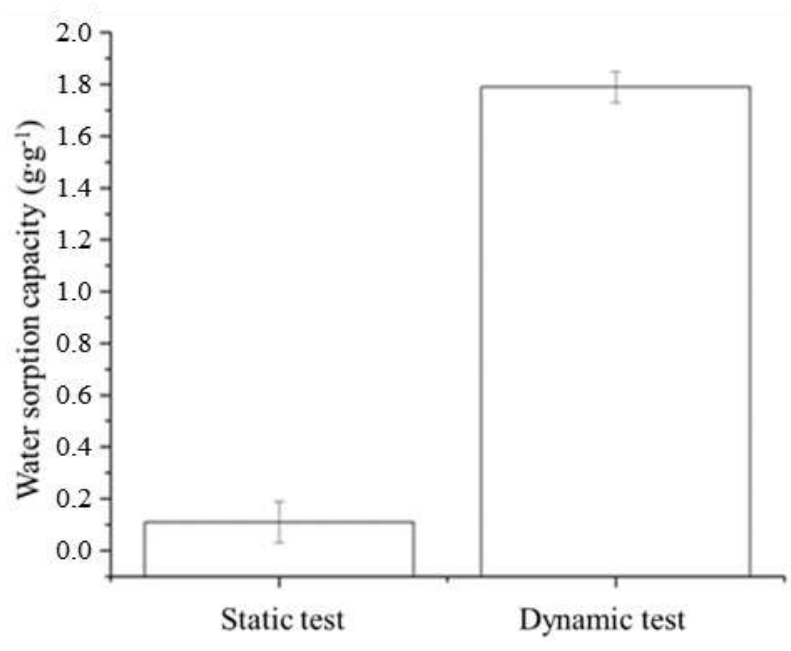

Source: Authors (2021).

It could be seen that there was a statistical difference between the static and the dynamic tests. In the static test, the overall water uptake was $0.15 \pm 0.05 \mathrm{~g} \cdot \mathrm{g}^{-1}$, whereas in the dynamic test the uptake was $1.80 \pm 0.3 \mathrm{~g} \cdot \mathrm{g}^{-1}$. The differences between the uptakes may be the result of the movement of the liquid through the PP blanket structure, which may have facilitated the 
diffusion and wetting of the material, since, due to the hydrophobic effect, the interface between the water and the sorbent is minimized, especially in a static environment.

The properties of the environment have a significant impact on the sorption capacity of the PP blanket. However, this influence is variable, as stated by Lee, Han, and Rowell (1999), Annunciado, Sydenstricker, and Amico (2005), and Wu, Fang, Qin, Wu, Mao, and Zhu (2014). Considering that, in a marine environment there is a perpetual water movement, it is important to verify if the mixing effect by the waves could affect negatively the sorbent performance; an excessive water uptake could cause a reduction of the sorption capacity relative to other sorbates, reduce the flotation of the material, or hinder the sorption due to the introduction of water molecules in the larger voids of the structure (Shaw, 1975; Wahi et al., 2013; Yang et al., 2009). However, despite the statistical difference between the sorption capacity of the static and dynamic tests (0.15 and $1.80 \mathrm{~g} \cdot \mathrm{g}^{-1}$, respectively), the overall uptake was quite smaller than the sorption of non-polar sorbates, which ranged from 5.38 to $12.36 \mathrm{~g} \cdot \mathrm{g}^{-1}$, indicating the presence of much weak interaction forces between water and the PP blanket than the interactions between the sorbent and the non-polar sorbates, even with the presence of the mixing effect.

\subsection{Sorption kinetics}

Sorption kinetic tests were carried out to verify what was the mechanism of the sorption process by the blanket. Figure 7 presents the removal percentages of diesel and petroleum as a function of sorption time and the concentration of the sorbate (the determination of lubricant oil removal percentage was not carried out due to its high viscosity).

Figure 7 - Diesel (a) and petroleum (b) removal percentages as functions of time and sorbate concentration.
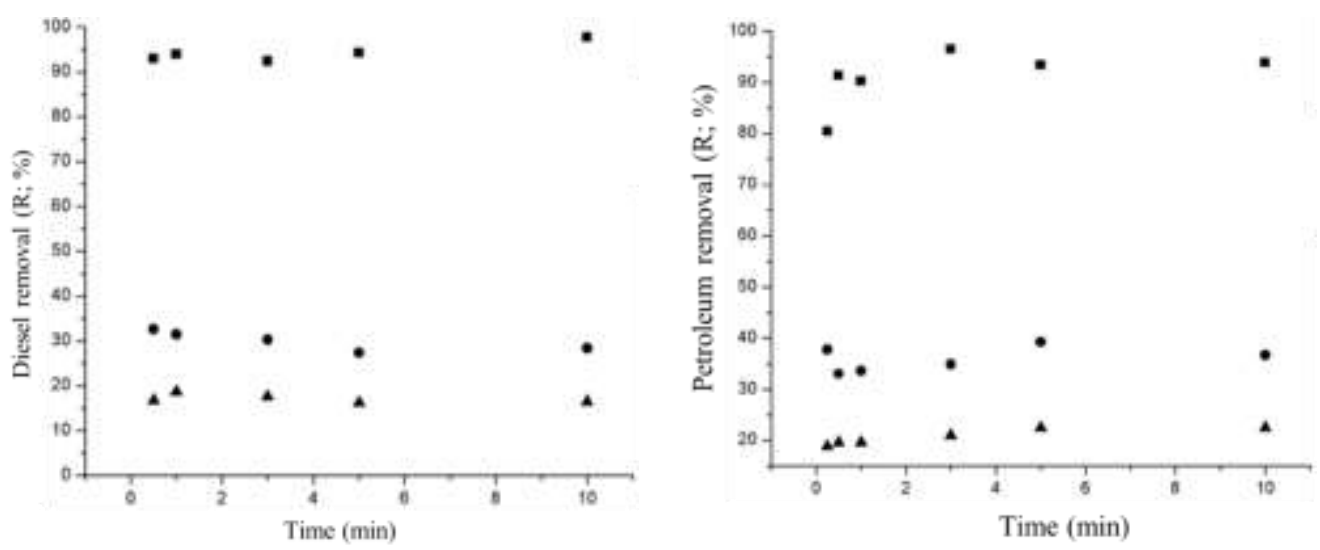

- $-1 \mathrm{~g} ; \bullet-3 \mathrm{~g} ; \boldsymbol{\Delta}-5 \mathrm{~g}$

Source: Authors (2021).

The diesel removal percentage varied with its concentration; the removal was higher than $90 \%$ at the lowest concentration ( $1 \mathrm{~g})$, whereas the removal was about $18-20 \%$ at the highest concentration $(5 \mathrm{~g})$. The petroleum removal percentage was quite similar to diesel, presenting itself slightly above $90 \%$ at the lowest concentration, with exception of one measurement. Some authors highlighted that petroleum fractions may dissolve in the aqueous medium, not being removed by the sorbent. There are works in the literature that comment on the solubilization of fractions of crude oil, and even heavy fractions of refined petroleum. Due to the more complex composition of petroleum relative to diesel, the former tends to present more water-soluble compounds than the latter, however, in the higher amounts of petroleum, this phenomenon may be suppressed due to the saturation of the aqueous layer, hindering the solubilization of more compounds from the organic layer (Dave \& Ghaly, 2011; Fernando, 2013; IMO, 2005; Kingston, 2002). 
The sorption capacity of the sorbates was evaluated as a function of time. The sorption curves of each sorbate are presented in Figure 8.

Figure 8 - Sorption capacities of diesel (a), petroleum (b), and lubricant oil (c).
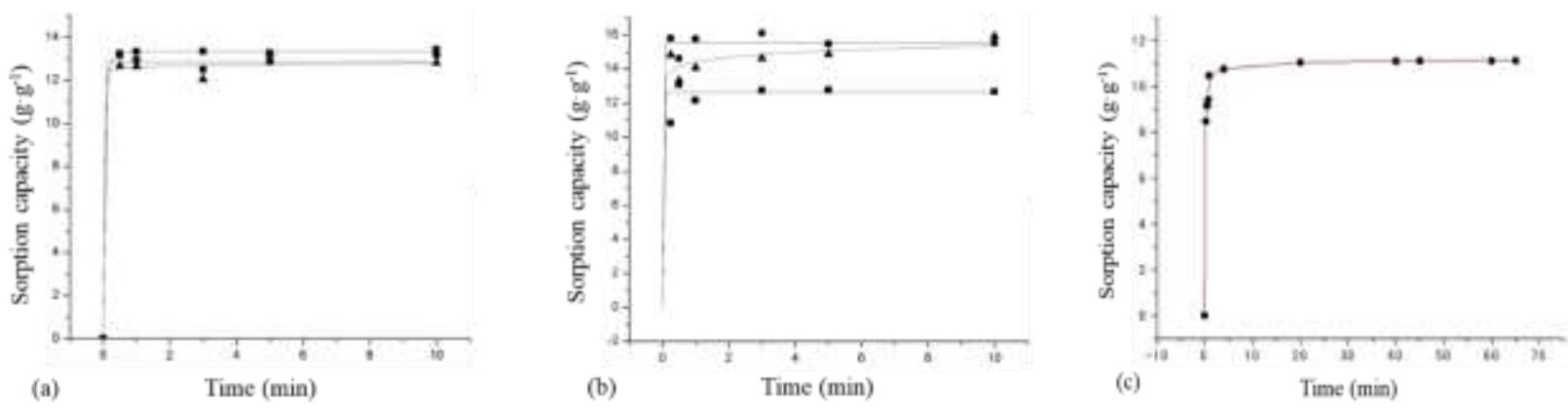

- $-1 \mathrm{~g} ; \bullet-3 \mathrm{~g} ; \boldsymbol{\Lambda}-5 \mathrm{~g}$

Source: Authors (2021).

According to Figure 8, it was possible to observe that, of all three sorbates, the diesel and petroleum presented quick sorptions, achieving the equilibrium in the first seconds of the test in all of the tested concentrations. The sorption capacities of the three oils were within the range of 11-16 $\mathrm{g} \cdot \mathrm{g}^{-1}$. However, there were statistical differences between the sorption capacities of each oil; petroleum presented the highest sorption at $3 \mathrm{~g}\left(16 \mathrm{~g} \cdot \mathrm{g}^{-1}\right)$, followed by diesel at $1 \mathrm{~g}\left(13 \mathrm{~g} \cdot \mathrm{g}^{-1}\right)$, and the lubricant oil $\left(11 \mathrm{~g} \cdot \mathrm{g}^{-1}\right)$. Relative to the sorption curve for the lubricant oil, the blanket reached equilibrium 20 min after the start of the test.

Li, Wu, Bubakir, Chen, Zhong, Liu, Ding, and Yang (2014) investigated the efficiency of fibers and blankets of PP manufactured by needless melt-electrospinning, evaluating three parameters: initial sorption capacity, adsorption capacity, and the equilibrium capacities for lubricant and peanut oils. The fibers and blankets produced without the needling process reached equilibrium after 15-20 min in contact with the sorbates, presenting results similar to the ones of the present work. Rengazamy et al. (2011) highlighted the influence of sorbate viscosity in the sorption process. Low-viscosity oils tend to migrate more quickly throughout the sorbent, which fosters its saturation and, consequently, also speeds up the draining process of the sorbate. On the other hand, more viscous liquids do not drain so easily, which renders a higher sorption capacity relative to less viscous liquids.

It is also important to note that no water was detected in the PP blanket after the sorption process, even after 60 min of contact with the water/sorbate mixture. Since the sorbent was put on the oil layer, probably the sorption of the oil through the pores induced a hydrophobic effect on the water, repelling it and avoiding its sorption by the sorbent structure.

The kinetic parameters for the pseudo-first and second orders were calculated for the three sorbates; the experimental and regression data are compiled in Table 2.

By analyzing Table 2, it is possible to observe that the kinetic model of pseudo-second order presented the best fit of the data, with $\mathrm{R}^{2}$ values equal or higher than 0.995 for all sorbates tested, whereas the $\mathrm{R}^{2}$ obtained for the pseudo-first-order model ranged between 0.032 and 0.862 , indicating a very poor fitting. Other kinetic studies also indicated that a pseudosecond-order fitting generally gives the best fitting overall, such as Ilgen (2014), who reported the pseudo-second-order as the kinetic model in the sorption of oleic acid by amberlyst A26 (OH); Sokker et al. (2011), who studied the sorption kinetics of crude oil by a chitosan/polyacrylamide-based hydrogel; Ahmad et al. (2005), who studied the sorption of palm oil residues by rubber powder, and Peng et al. (2013), who used cellulase-treated corn stalk in the sorption of oil. 
Table 2 - Kinetic parameters of the pseudo-first and pseudo-second-order models and the quality of the fitting.

\begin{tabular}{|c|c|c|c|c|c|c|}
\hline Kinetic model & Sorbate & $\begin{array}{l}\text { Sorbate concentration } \\
\quad\left(\mathrm{g} \cdot 100 \mathrm{~mL}^{-1}\right)\end{array}$ & $\mathrm{q}_{\mathrm{e}} \exp$ & qe calc. & $\mathrm{k}_{1} ; \mathrm{k}_{2}^{*}$ & $\mathrm{R}^{2}$ \\
\hline \multirow{9}{*}{$\begin{array}{l}\text { Pseudo-first } \\
\text { order }\end{array}$} & \multirow{3}{*}{ Diesel } & 1 & 13.13 & 0.08 & -0.20 & 0.138 \\
\hline & & 3 & 13.18 & 0.34 & 0.06 & 0.380 \\
\hline & & 5 & 12.81 & 0.75 & 0.21 & 0.123 \\
\hline & \multirow{3}{*}{ Petroleum } & 1 & 12.66 & 0.14 & 0.12 & 0.032 \\
\hline & & 3 & 15.53 & 1.62 & 0.29 & 0.310 \\
\hline & & 5 & 15.92 & 6.38 & 0.75 & 0.862 \\
\hline & \multirow{3}{*}{ Lubricant } & 1 & 12.15 & 0.27 & 0.64 & 0.060 \\
\hline & & 3 & 13.52 & 2.85 & -0.14 & 0.034 \\
\hline & & 5 & 13.67 & 7.78 & 0.28 & 0.071 \\
\hline \multirow{9}{*}{$\begin{array}{l}\text { Pseudo-second } \\
\text { order }\end{array}$} & \multirow{3}{*}{ Diesel } & 1 & 13.13 & 13.14 & -2.51 & 0.999 \\
\hline & & 3 & 13.18 & 13.21 & 1.14 & 0.999 \\
\hline & & 5 & 12.81 & 12.95 & 1.35 & 0.999 \\
\hline & \multirow{3}{*}{ Petroleum } & 1 & 12.66 & 12.70 & 5.63 & 0.999 \\
\hline & & 3 & 15.53 & 15.52 & 4.60 & 0.999 \\
\hline & & 5 & 15.92 & 15.97 & 0.38 & 0.999 \\
\hline & \multirow{3}{*}{ Lubricant } & 1 & 10.94 & 11.11 & 21.2 & 0.995 \\
\hline & & 3 & 10.99 & 10.86 & 16.7 & 0.996 \\
\hline & & 5 & 11.02 & 11.04 & 12.2 & 0.995 \\
\hline
\end{tabular}

* $-\mathrm{k}_{1}$ : rate constant of the pseudo-first order model; $\mathrm{k}_{2}$ : rate constant of the pseudo-second order model. Source: Authors (2021).

The pseudo-first and pseudo-second-order kinetics are generally related to the underlying adsorption mechanism of the system; however, recent analyses cast doubt on the real applicability of using the kinetic models to determine the absorption mechanism (Simonin, 2016). However, literature agrees that systems that fit better to pseudo-second-order kinetics are the ones that reach equilibrium quickly (Canzano, Iovino, Leone, Salvestrini, and Capasso., 2012; Simonin, 2016), as observed in the sorption tests, in which equilibrium was achieved in less than $15 \mathrm{~min}$ for all sorption curves (Figure 8).

\subsection{Adsorption isotherms}

The linear fit and the determination coefficient of the sorption data of the diesel oil in the three isotherm models are presented in Figure 9.

Figure 9 - Fitting of the experimental sorption data of diesel on the linearized Langmuir (a), Freundlich (b), and Temkin (c) isotherms.

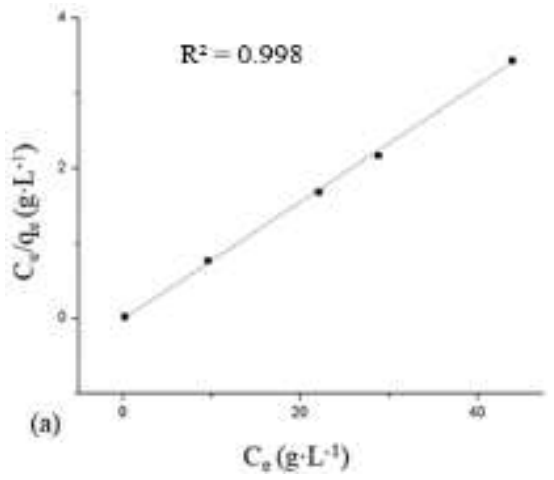

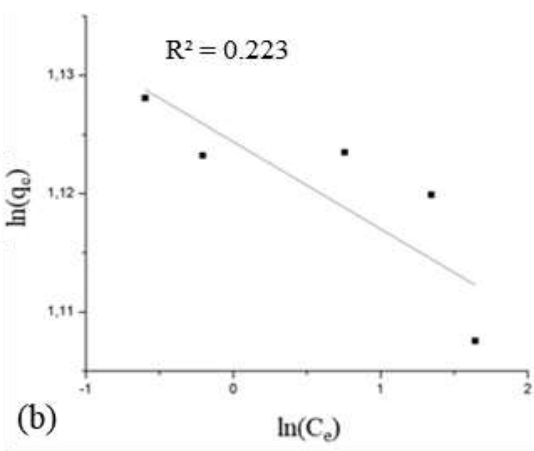

Source: Authors (2021).

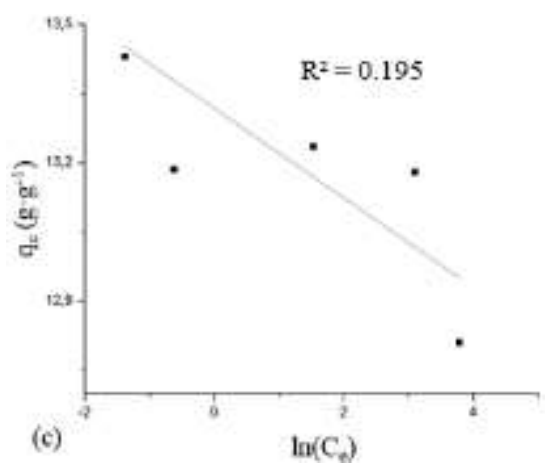

(c) 
By verifying Figure 9, it was possible to observe that the Langmuir isotherm presented the best fit $\left(\mathrm{R}^{2}=0.998\right)$ when compared to the Freundlich $\left(\mathrm{R}^{2}=0.223\right)$ and Temkin $\left(\mathrm{R}^{2}=0.195\right)$ models. In this sense, the adsorption process between the diesel oil and the PP blanket is mostly by a monolayer, in which the sorbate interacts at the surface of the sorbent, but only to the extent of a thin layer (Ahmad et al., 2005). Considering a process of sorption and removal of the sorbate (in this case, the diesel oil), monolayer adsorption tends to yield smaller overall sorption capacities, but the sorbent recovery process also tends to be more efficient (Ahmad et al., 2005; Sokker et al., 2011). The obtained RL values for the PP blanket and diesel oil system ranged between 0.19 and 0.55 , indicating a favorable sorption process.

Figure 10 presents the linear fit of the sorption data of petroleum in the three isotherm models.

Figure 10 - Fitting of the experimental sorption data of petroleum on the linearized Langmuir (a), Freundlich (b), and Temkin (c) isotherms.

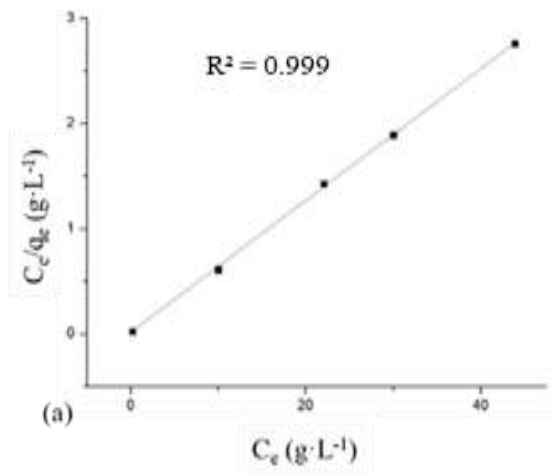

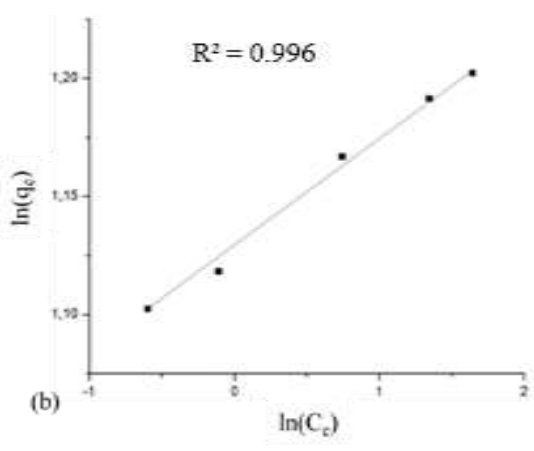

Source: Authors (2021).

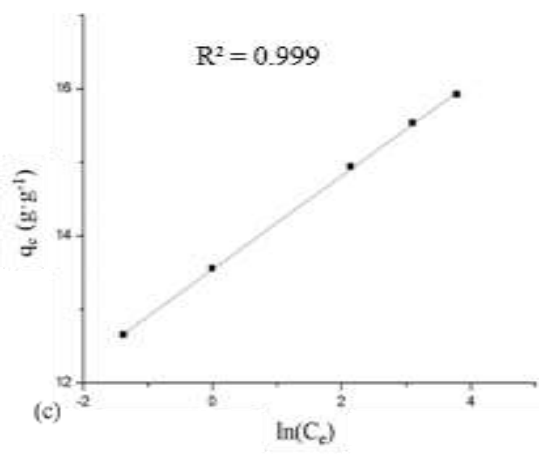

According to Figure 10, unlike the behavior observed for the diesel oil (Figure 9), all isotherm models presented an excellent fit relative to petroleum, with determination coefficients in the range of 0.996-0.999. Considering the good data fit to the three models, the petroleum sorption probably is of the multilayer kind and may be the result of the higher viscosity of this sorbate, which increases the interactions between sorbate layers. The higher viscosity may hinder the sorption process, decreasing the overall sorption capacity. However, multilayer adsorption also increases the capacity due to the stronger interaction between sorbate layers (Ahmad et al., 2005; Sokker et al., 2011). The calculated $R_{L}$ values for the PP blanket and petroleum system ranged between $4.5 \cdot 10^{-4}$ and $2.0 \cdot 10^{-2}$, indicating a favorable adsorption process, as observed with diesel oil.

The regression parameters of the diesel oil and petroleum relative to each isotherm model are compiled in Table 3 .

By observing Table 3, it is possible to observe that diesel oil had an excellent fit to Langmuir isotherm, whereas petroleum fitted very well to the three models. The higher viscosity of petroleum may have played a role in adsorbing more strongly to the PP blanket, which may have also helped to generate a multilayer sorbate structure. On the other hand, the smaller dynamic viscosity of diesel prevented it from effectively forming a multilayer sorbate structure, thus, following the Langmuir model.

Alihosseini, Taghikhani, Safekordi, and Bastani (2010) reported that the isotherms of Freundlich $\left(\mathrm{R}^{2}=0.988-0.989\right)$ and Temkin $\left(\mathrm{R}^{2}=0.974-0.980\right)$ presented a better fit to experimental data than the Langmuir isotherm $\left(\mathrm{R}^{2}=0.913-0.935\right)$ in the adsorption of two kinds of crude petroleum by expanded perlite. Ahmad et al. (2005) also reported that the Freundlich model presented an excellent correlation $\left(\mathrm{R}^{2}=0.998-0.999\right)$ with the experimental data of the sorption of palm oil by chitosan powder and flakes. Sokker et al. (2011) cited that the Langmuir isotherm presented a better fit $\left(\mathrm{R}^{2}=0.984\right)$ than the Freundlich isotherm $\left(\mathrm{R}^{2}=0.750\right)$ in the adsorption of crude petroleum by a polyacrylamide hydrogel. Foo and Hameed (2013), who evaluated the adsorption of methylene blue by granulous activated charcoal, observed that the Langmuir isotherm presented the 
best fit $\left(R^{2}=0.999\right)$, whereas the Temkin isotherm presented $R^{2}$ values in the range of $0.829-0.880$.

Table 3 - Regression parameters of the isotherm models.

\begin{tabular}{|c|c|c|c|}
\hline Sorbate & Isotherm model & Parameter & Value \\
\hline \multirow{9}{*}{ Diesel oil } & \multirow{3}{*}{ Langmuir } & $\mathrm{K}_{\mathrm{L}}$ & 0.078 \\
\hline & & $\mathrm{q}_{\mathrm{o}}$ & 12.804 \\
\hline & & $\mathrm{R}^{2}$ & 0.999 \\
\hline & \multirow{3}{*}{ Freundlich } & $\mathrm{K}_{\mathrm{f}}$ & 13.316 \\
\hline & & $1 / \mathrm{n}$ & -0.007 \\
\hline & & $\mathrm{R}^{2}$ & 0.223 \\
\hline & \multirow{3}{*}{ Temkin } & $\mathrm{A}$ & $2.350 \cdot 10^{-60}$ \\
\hline & & $\mathrm{b}$ & $-25,713.40$ \\
\hline & & $\mathrm{R}^{2}$ & 0.195 \\
\hline \multirow{9}{*}{ Petroleum } & \multirow{3}{*}{ Langmuir } & $\mathrm{K}_{\mathrm{L}}$ & 4.180 \\
\hline & & $\mathrm{q}_{\mathrm{o}}$ & 15.948 \\
\hline & & $\mathrm{R}^{2}$ & 0.999 \\
\hline & \multirow{3}{*}{ Freundlich } & $\mathrm{K}_{\mathrm{f}}$ & 13.474 \\
\hline & & $1 / \mathrm{n}$ & 0.045 \\
\hline & & $\mathrm{R}^{2}$ & 0.996 \\
\hline & \multirow{3}{*}{ Temkin } & A & $1.68 \times 10^{9}$ \\
\hline & & $\mathrm{b}$ & $3,915.54$ \\
\hline & & $\mathrm{R}^{2}$ & 0.999 \\
\hline
\end{tabular}

Source: Authors (2021).

Relative to the different isotherms, the Langmuir model considers that adsorption occurs in a relatively even surface, following a monolayer structure; all active sites are regarded as the same and the sorption of a molecule by an active site is not influenced by the occupation of the neighboring sites, and the sorption heat is independent of the surface size that is exposed. The main consideration of this model is the simplification that renders the sorption heat independent of the size of the surface exposed to adsorption (Ayawei et al., 2017; Saruchi \& Kumar, 2019).

The Freundlich isotherm is used to model adsorption processes that occur on heterogeneous surfaces. This isotherm gives an expression that defines the surface heterogeneity and the exponential distribution of active sites and their energies, corresponding to a logarithmic variation of a summation of Langmuir equation distributions. This model is also used to describe non-ideal and reversible multilayer adsorption onto heterogeneous surfaces (Ayawei et al., 2017).

The Temkin isotherm model considers indirect adsorbate/adsorbate interactions on the adsorption process. This model also assumes that the heat of adsorption of all molecules in the layer decreases linearly with an increasing surface coverage (Ayawei et al., 2017; Saruchi \& Kumar, 2019).

It is important to observe that the adsorption mechanism is highly dependent on the physicochemical properties of both the adsorbate and the adsorbent (Ahmad et al., 2005). Thus, the same sorbent may have distinct adsorption mechanisms when in contact with different adsorbates, such as the system PP blanket/diesel oil, which presented a better fit to Langmuir isotherm, and the PP blanket/petroleum isotherm, which presented an excellent fit to the three isotherm models (Langmuir, Freundlich, and Temkin).

Considering the isotherms that fitted betted to the experimental data, the sorption of diesel oil by the PP blanket probably followed mostly a monolayer interaction, with the diffusion of the sorbed material into the polymer structure. This allowed for further sorption of the diesel. On the other hand, the sorption of petroleum by the PP blanket fitted to all three isotherms; in this case, two or more sorption mechanisms occurred simultaneously, with the formation of both mono and multilayers. This may be the result of differences between the physicochemical properties of each sorbate or even due to the different chemical compositions. 


\subsection{Flotation tests}

Regarding the flotation tests, all samples floated in both the dynamic and static floating tests. Since the blanket density was quite smaller than the one of water $(0.10 \mathrm{~g} \cdot \mathrm{cm}-3$ against $1.00 \mathrm{~g} \cdot \mathrm{cm}-3$, respectively), most of the sorbent remained above the waterline. This is desirable in the removal of low-density oils since nearly all of the sorbate will remain in a layer above the water. It could also be observed that the sorbent had not induced a change in the water properties, such as color and odor. All of the PP blanket samples also maintained their structural integrity after the flotation tests, at least macroscopically.

\subsection{Reusability}

Cycles of sorption-desorption were carried out to verify the performance of the PP blanket, its reusability, and the effectiveness of several sorbate removal procedures. Figure 11 presents the results of the test cycles with different sorbate removal procedures.

The PP blankets presented a lubricant oil sorption capacity at the end of the first cycle of $9.05 \pm 0.23 \mathrm{~g} \cdot \mathrm{g}^{-1} ; 8.57 \pm 0.22$ $\mathrm{g} \cdot \mathrm{g}^{-1}$; and $8.90 \pm 0.54 \mathrm{~g} \cdot \mathrm{g}^{-1}$ for the extraction procedures of mechanical pressing, roller pressing, and centrifugation, respectively. There was also a decreasing trend of the sorption capacity with the number of cycles, with stabilization after the second cycle.

Considering the tested samples, the overall reduction of sorption capacity between the first and second cycles was 79.34\% for mechanical pressing, $66.86 \%$ for roller pressing, and $30.23 \%$ for centrifugation. From the second cycle on, the sorption capacity of the samples remained nearly constant for all sorbent removal methods studied. The sorption capacities after the second cycle for the mechanical pressing were $2.11 \pm 0.69 \mathrm{~g} \cdot \mathrm{g}^{-1}, 3.22 \pm 0.38 \mathrm{~g} \cdot \mathrm{g}^{-1}$ for the roller pressing, and $6.69 \pm 0.29 \mathrm{~g} \cdot \mathrm{g}^{-1}$ for centrifugation, a difference of more than three times between the highest and smallest sorption capacities.

Figure 11 - Lubricant oil sorption capacity of the PP blankets as a function of the test cycles and the sorbate removal procedure.

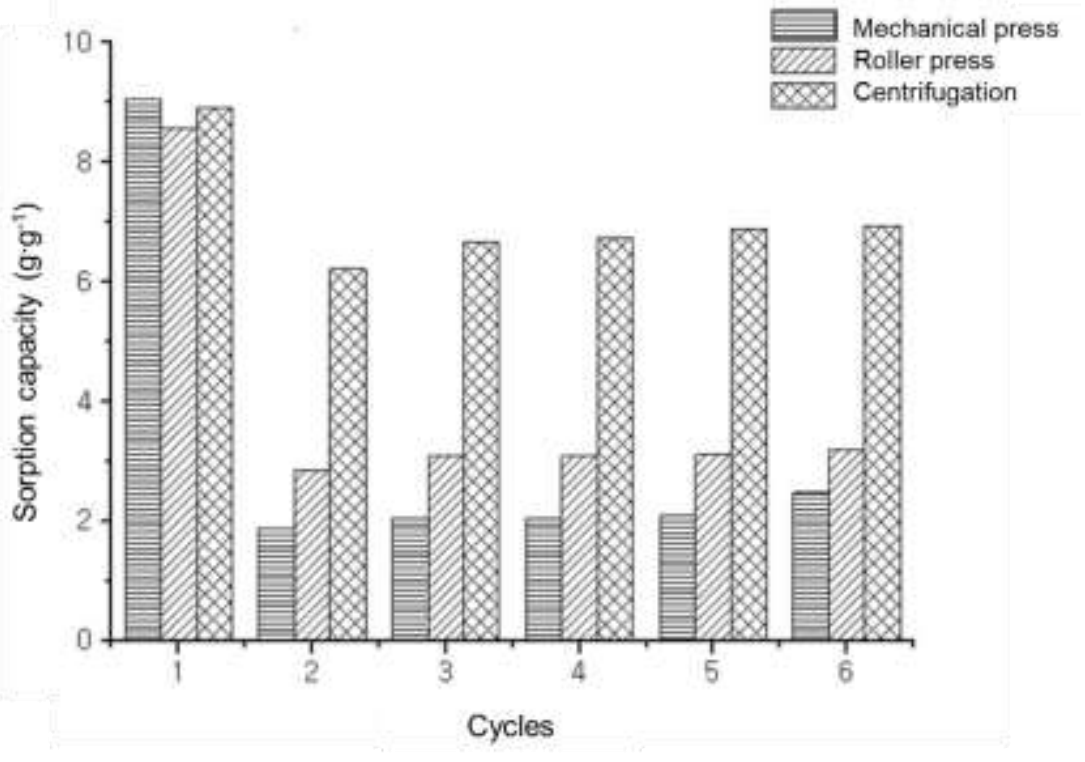

Source: Authors (2021).

Tanobe (2007) highlighted that the sorption capacity of any sorbent material is reduced when the material is reused due to the mechanical stress it undergoes during the sorbate removal steps, compromising the fiber and pore structures. In this sense, it could be verified that the PP blanket samples have had an important reduction in their thickness and increase in their length and width when the sorbed oil was removed by pressing (both by mechanical and roller pressing). On the other hand, 
when centrifuged, the samples have not presented any observable change in their dimensions.

Considering the sorbent mass at the start of each cycle, the remaining sorbate mass was $20.48 \pm 1.29 \mathrm{~g}$ when using the mechanical press, $17.72 \pm 0.95 \mathrm{~g}$ for the roller press, and $4.26 \pm 0.16 \mathrm{~g}$ when using the centrifuge. These values are associated with the overall sorbate removal. The centrifugation of the saturated PP blanket was the better option when comparing the three. The overall oil removal efficiency considering the six cycles was $95.56 \pm 0.41 \%$ for the centrifugation, whereas the roller pressing and mechanical pressing have presented removal efficiencies of $78.80 \pm 4.09 \%$ and $67.33 \pm 1.27 \%$, respectively.

Inagaki, Kawahara, and Konno (2002) studied the reusability of carbonized fibers of fir tree (Abis sachalinensis Fr. Schm), in the sorption of heavy oil from classes A (less viscous) and C (more viscous). The oil removal was carried out through filtration with a pressure difference of $5 \mathrm{kPa}$ and washing with $\mathrm{n}$-hexane, in a five-cycle process. Despite the sorption capacity decreased as the number of cycles increased, the overall oil removal was high (about 90\%) for the A-class oil, and nearly $100 \%$ for the C-class oil. A similar performance was observed with the centrifugation of the blankets (overall removal of $95.56 \%$ ). However, it is very important to cite that the tests carried out by Inagaki et al. (2002) employed n-hexane to dissolve the sorbate, whereas in the present work only the centrifugal force was employed to remove the sorbed material, both methods rendering quite similar results.

$\mathrm{Hu}$, Liu, Zou, Gu, Chai, and Li (2013) studied the reusability of graphited rubber gels in the sorption of diesel in a 30cycle process, the removal of the sorbate was by centrifugation (4000 rpm for $3 \mathrm{~min}$ ). The authors concluded that, even after 30 cycles, the sorption capacity of the sorbent remained similar to the capacity in the first cycle (maximum sorption capacity). The authors attributed the property of the elastomer to deform and return to the original form after the removal of the sorbent as the main factor for the material to maintain the sorption capacity nearly unchanged. However, a fraction of the sorbed diesel remained in the sorbent.

Lin et al. (2012) evaluated the reusability of PP fibers as sorbent for 5 W40 lubricant oil, and the sorbate removal was carried out by mechanical compression, in a similar way than in the present work. The starting sorption capacity was $4.3 \mathrm{~g} \cdot \mathrm{g}^{-1}$; from the second to the eighth cycle, there was a progressive decrease of the sorption capacity, which stabilized from the ninth cycle up to the hundredth at $1.7 \mathrm{~g} \cdot \mathrm{g}^{-1}$, about $40 \%$ of the initial capacity of the PP fibers. The authors associated the reduction in sorption capacity with a low fiber elasticity. It could be seen that, when compared to the previous authors, in the present study a greater decrease in the sorption capacity of the sorbent occurred when the sorbate was removed through mechanical pressing, similar when the removal was carried out by roller pressing, and smaller when the sorbate was removed by centrifugation.

In this sense, higher elasticity may help the elastic deformation of the fiber structure and pores, helping to restore the material structure before pressing, which is responsible for sorbate sorption and retention. This also explains why the blankets treated by centrifugation had the lowest reduction in their sorption capacity because centrifugation does not cause the material do support a high mechanical strain, reducing the overall changes in the structure and preserving the pores and the fibers.

Choi and Cloud (1992) tested the reusability of PP fibers in the sorption of light petroleum emulsified with artificial seawater. The sorbate was removed by roller pressing with a pressure of $50 \mathrm{psi}(344.7 \mathrm{kPa})$. In the first cycle, the sorption capacity of the PP fibers was $11.3 \mathrm{~g} \cdot \mathrm{g}^{-1}$, in the second and third cycles, is reduced to $9.4 \mathrm{~g} \cdot \mathrm{g}^{-1}$, a decrease of $16.8 \%$. This value was smaller than the one observed in this work. The remaining oil mass was also smaller, $1.70 \mathrm{~g}$ against $17.72 \mathrm{~g}$.

Radetic, Jocic, Jovanic, Petrovic, and Thomas (2003) demonstrated the reusability of recycled wool wastes by compression through five cycles. The authors observed that the sorption capacity, despite decreasing in each cycle, was not significantly affected and the sorbate removal was also considered satisfactory. The authors concluded that the sorbent was effective and a possible alternative to replace synthetic sorbents that are commercially available.

Wu et al. (2014) compared the reusability of polyurethane (PU) foams in which the sorbate removal was carried out by compression. The tests were performed using lubricant oil in fifteen cycles. The authors reported a progressive decrease of 
the sorption capacity in each cycle; at the end of the cycles, the overall capacity stabilized at about $70 \%$ of the starting capacity. The efficiency was higher than the ones whose sorbate removal was carried out by pressing (both mechanical and roller) and similar to the efficiency observed in the centrifugation process.

Considering the mostly amorphous characteristic of the PP blanket, the mechanical pressing and roller press both may induce changes in the overall structure and orientation of the fibers, probably increasing their packing and reducing the size and number of voids, this may hinder the overall sorption process. In this sense, centrifugation, despite applying mechanical force to remove the sorbed oils, very probably does not cause any major changes in the packing and orientation of the sorbent fibers, maintaining the overall sorption capacity of the PP blanket relative to other sorbate removal methods that employ direct mechanical force on the fibers (mechanical and roller press).

\section{Conclusion}

The average sorption capacities of the PP blanket for diesel, petroleum, and lubricant oil were 5.46, 12.30, and $18.64 \mathrm{~g} \cdot \mathrm{g}^{-1}$, respectively. The blanket presented a similar performance in the short- and long-term tests, indicating that in about 15 min the sorbent was saturated with the studied sorbates. The water uptake was different between the static and dynamic tests. Relative to flotation tests, all samples floated, with no macroscopic changes to both the blanket and the test seawater. The sorption process of all three sorbates followed pseudo-second-order kinetics, indicating a quick saturation (equilibrium) of the sorbent when in contact with the sorbates. The adsorption data of diesel oil presented a better fit to the Langmuir isotherm, indicating that the sorption of diesel oil by the PP blanket probably followed mostly a monolayer interaction, with the diffusion of the sorbed material into the polymer structure. The sorption data for petroleum presented an excellent fit to all three isotherm models (Langmuir, Freundlich, and Temkin), indicating that two or more sorption mechanisms occurred simultaneously, with the formation of both mono and multilayers. Regarding the blanket reusability, the PP blanket sorption capacity was influenced by both the sorbate removal method and the number of cycles. The sorption capacity of the material stabilized after the second cycle and the samples whose sorbate removal was carried out by centrifugation have presented better sorption capacities, very likely due to a smaller strain and deformation on the polymer structure.

\section{References}

Abdullah, M. A., Rahmah, A. R., \& Man, Z. (2010). Physicochemical and sorption characteristics of Malaysian Ceiba pentandra (L.) Gaertn. as a natural oil sorbent. Journal of Hazardous Materials, 177:683-691. DOI: 10.1016/j.jhazmat.2009.12.085

Aghajanloo, K., \& Pirooz, M.D. (2011). The Simulation of the oil weathering processes in marine environment. International Conference on Environmental and Computer Science, 19:29-34.

Ahmad, A. L., Sumathi, S., \& Hameed, B. H. (2005). Adsorption of residue oil from palm oil mill effluent using powder and flake chitosan: Equilibrium and kinetic studies. Water Research, 32:2483-2494.

Alihosseini, A., Taghikhani, V., Safekordi, A. A., \& Bastani, D. (2010). Equilibrium sorption of crude oil by expanded perlite using different adsorption isotherms at 298.15 K. International Journal of Environmental Science and Technology, 7:591-598.

American Society of Testing and Materials (2012) F726-12: Standard test methods for sorbent performance of adsorbents. ASTM, West Conshohocken, USA.

Annunciado, T. R., Sydenstricker, T. H. D., \& Amico, S. C. (2005). Experimental investigation of various vegetable fibers as sorbent materials for oil spills. Marine Pollution Bulletin, 50:1340-1346.

Ayawei, N., Ebelegi, A. N., \& Wankasi, D. (2017). Modelling and Interpretation of Adsorption Isotherms. Hindawi Journal of Chemistry, 2017:3039817. DOI: $10.1155 / 2017 / 3039817$

Bansal, S., Arnim, V., Stegmaier, T., \& Planck, H. (2011). Effect of fibrous filter properties on the oil-in-water-emulsion separation and filtration performance. Journal of Hazardous Materials, 190:45-50. DOI: 10.1016/j.jhazmat.2011.01.134

Bayona JM, Domínguez C, Albaigés J (2015) Analytical developments for oil spill fingerprinting. Trends in Environmental Analytical Chemistry, 5:26-34. DOI: 10.1016/j.teac.2015.01.004

Branpud, J., \& Immergut, E. H. (1989). Polymer Handbook. Wiley Interscience, New York. 
Callister, W. D., \& Rethwisch, D. G. (2010). Materials Science and Engineering: an introduction. Wiley, New York.

Canciam, C. A. (2012). Estimativa da energia de ativação de fluxo dos óleos lubrificantes SAE 30, SAE 40 e SAE 50. Revista da Universidade Vale do Rio Verde, 10:202-210.

Canzano, S., Iovino, P., Leone, V., Salvestrini, S., \& Capasso, S. (2012). Use and Misuse of Sorption Kinetic Data: A Common Mistake that Should be Avoided. Adsorption Science and Technology, 30:217-225.

Choi, H., \& Cloud, R. M. (1992). Natural Sorbents in oil spill cleanup. Environmental Science and Technology, 26:772-776.

Companhia Ambiental do Estado de São Paulo. (2014). Gerenciamento de riscos. CETESB, São Paulo, Brazil.

D’Andrea, M. D., Facro, M. D., \& Reddy, G. K. (2013). Health consequences among subjects involved in Gulf oil spill clean-up activities. American Journal of Medicine, 126:966-974. DOI: 10.1016/j.amjmed.2013.05.014

Dave, D., \& Ghaly, A. E. (2011). Remediation technologies for marine oil spills: a critical review and comparative analysis. American Journal of Environmental Science, 7:423-440. DOI: 10.3844/ajessp.2011.423.440

Fernando, H. J. S. (2013). Handbook of environmental fluid dynamics. CRC Press, Boca Raton, USA.

Foo, K. Y., \& Hameed, B. H. (2013). Utilization of oil palm biodiesel solid residue as renewable sources for preparation of granular activated carbon by microwave induced KOH activation. Bioresource Technology, 130:696-702.

Hasan, S. W., Ghannam, M. T., \& Esmail, N. (2010). Heavy crude oil viscosity reduction and rheology for pipeline transportation. Fuel, 89:1095-1100. DOI: 10.1016/j.fuel.2009.12.021

Hu, Y., Liu, X., Zou, J., Gu, T., Chai, W., \& Li, H. (2013). Graphite/isobutylene-isoprene rubber highly porous cryogels as new sorbents for oil spills and organic liquids. Applied Materials \& Interfaces, 5:7737-7742.

Ilgen, O. (2014) Adsorption of oleic acid from sunflower oil on Amberlyst A26 (OH). Fuel Processing Technology, 118:69-74.

Inagaki, M., Kawahara, A., \& Konno, H. (2002). Sorption and recovery of heavy oils using carbonized fir fibers and recycling. Carbon, 40:105-111.

International Maritime Organization. (2005). Manual on oil pollution. IMO, London, UK.

Jahnson, P. (2013). Modern Gas Turbine Systems - High Efficiency, Low Emission, Fuel Flexible Power Generation. Sawston, Woodhead Publishing.

Johnson, R. F., Manjrekar, T. G., \& Halligan, J. E. (1973). Removal of oil from water surfaces by sorption on unstructured fibers. Environmental Science and Technology, 7:439-443. DOI: 10.1021/es60077a003

Kingston, P. F. (2002). Long-term environmental impact of oil spills. Spill Science \& Technology Bulletin, 7:53-61.

Lee, B. G., Han, J. S., \& Rowell, R. M. (1999). Oil sorption by lignocellulosic fibers. In: Lee, B. G., Han, J. S., \& Rowell, R. M. (Eds.). Kenaf properties, processing and products. Mississippi State: Mississippi State University, USA.

Li, H., Wu, W., Bubakir, M. M., Chen, H., Zhong, X., Liu, Z., Ding, Y., \& Yang, W. (2014) Polypropylene fibers fabricated via a needleless meltelectrospinning device for marine oil-spill cleanup. Journal of Applied Polymer Science, 131:40080-40089.

Líbano, E. V. D. G., Visconte, L. L. Y., \& Pacheco, E. B. A. V. (2012). Propriedades térmicas de compósitos de polipropileno e bentonita organofílica. Polímeros, 22:430-435. doi: 10.1590/S0104-14282012005000063

Lim, T. T., \& Huang, X. (2007). Evaluation of kapok (Ceiba pentandra (L.) Gaertn.) as a natural hollow hydrophobic-oleophilic fibrous sorbent for oil spill cleanup. Chemosphere, 66:955-963. DOI: 10.1016/j.chemosphere.2006.05.062

Lin, J., Shang, Y., Ding, B., Yang, J., Yu, J., \& Al-Deyab, S. S. (2012). Nanoporous polystyrene fibers for oil spills cleanup. Marine Pollution Bulletin, 64:347-352. DOI: 10.1016/j.marpolbul.2011.11.002

Nurhadi, B., \& Roos, Y. H. (2016). Dynamic water sorption for the study of amorphous content of vacuum-dried honey powder. Powder Technology, 301:981-988. DOI: 10.1016/j.powtec.2016.07.055

Peng, D., Lan, Z., Guo, C., Yang, C., \& Dang, Z. (2013). Application of cellulase for the modification of corn stalk: leading to oil sorption. Bioresource Technology, 137:414-418. DOI: 10.1016/j.biortech.2013.03.178

Pereira, T. M. C., Domingos, E., Castro, E. V. R., Romão, W., Sena, G. L., \& Sena, D. R. (2014). Efeito dos solventes orgânicos sobre o comportamento físico-químico do polietileno de alta densidade (PEAD) e polipropileno (PP). Polímeros, 24:300-306. DOI: 10.4322/polimeros.2014.045

Qi, X., Jia, Z., Yang, Y., \& Liu, H. (2011). Sorption capacity of new type oil adsorption felt for potential application to ocean oil spill. Procedia Environmental Sciences, 10:849-853. DOI: 10.1016/j.proenv.2011.09.137

Radetic, M. M., Jocic, D. M., Jovanic, P. M., Petrovic, Z. L. J., \& Thomas, H. F. (2003). Recycled wool-based nonwoven material as an oil sorbent. Environmental Science and Technology, 37:1008-1012.

Rana, C., Pramanik, S., Martin, M., De Wit, A. \& Mishra, M. (2019). Influence of Langmuir adsorption and viscous fingering on transport of finite size samples in porous media. Physical Review Fluids, 4(10):104001. DOI: 10.1103/PhysRevFluids.4.104001

Rengazamy, R. S., Das, D., \& Karan, C. P. (2011). Study of oil sorption behavior of filled and structured fiber assemblies made from polypropylene, kapok and milkweed fibers. Journal of Hazardous Materials, 186:526-532. DOI: 10.1016/j.jhazmat.2010.11.031 
Rosa, A. H., Fraceto, L. F., \& Moshini-Carlos, V. (2012). Meio ambiente e sustentabilidade. Bookman, Porto Alegre, Brazil.

Rosa, S. M. L. (2007). Estudo das propriedades de compósitos de polipropileno com casca de arroz. Master's dissertation, Universidade Federal do Rio Grande Sul, Porto Alegre, Brazil.

Saruchi, \& Kumar, V. S. (2019). Adsorption kinetics and isotherms for the removal of rhodamine B dye and Pb+2 ions from aqueous solutions by a hybrid ion-exchanger. Arabian Journal of Chemistry, 12:316-329. DOI: 10.1016/j.arabjc.2016.11.009

Shackelford, J.F. (2000). Introduction to materials science for engineers. Prentice Hall, New Jersey, USA.

Shaw, D. J. (1975). Introdução à química dos colóides e de superfícies. 1st edn. Editora da Universidade de São Paulo, São Paulo, Brazil.

Simonin, J. P. (2016). On the comparison of pseudo-first order and pseudo-second order rate laws in the modeling of adsorption kinetics. Chemical Engineering Journal, 300:254-263. DOI: 10.1016/j.cej.2016.04.079

Simonovic, B. R., Arandelovic, D., Jovanovic, M., Kovacevic, B., Pezo, L., \& Jovanovic, A. (2009). Removal of mineral oil and wastewater pollutants using hard coal. Chemical Industry \& Chemical Engineering Quarterly, 15:57-62.

Singh, V. (2013). Crude oil sorption by raw cotton. Industrial \& Engineering Chemistry Research, 52:6277-6281. DOI: 10.1021/ie4005942

Sokker, H. H., El-Sawy, N. M., Hassan, M. A., \& El-Anadouli, B. E. (2011). Adsorption of crude oil from aqueous solution by hydrogel of chitosan-based polyacrylamide prepared by radiation induced graft polymerization. Journal of Hazardous Materials, 190:359-365. DOI: 10.1016/j.jhazmat.2011.03.055.

Souza, E. S., \& Triguis, J. A. (2005). Degradação do petróleo em derrames no mar - intemperismo x biorremediação. Proceedings of the III Congresso Brasileiro de P\&D em Petróleo e Gás, Salvador, Brazil.

Standard Methods for the Examination of Water and Wastewater. (2012). Oil and grease. APHA, Washington, USA.

Tanobe, V. (2007). Desenvolvimento de sorventes à base de espumas de poliuretanos flexíveis para para o setor do petróleo. PhD thesis, Universidade Federal do Paraná, Curitiba, Brazil.

Teas, C., Kalligeros, S., Zanikos, F., Stournas, S., Lois, E., \& Anastopoulos, G. (2001). Investigation of the effectiveness of absorbent materials in oil spills clean up. Desalination, 140:259-264. DOI: 10.1016/S0011-9164(01)00375-7

Tokumoto, S. (2003). Deformação plástica do polipropileno isotático: aspectos do mecanismo, propriedades e morfologia. PhD thesis, Universidade Federal do Rio Grande do Sul, Porto Alegre, Brazil.

Trombetta, E. (2010). Utilização de fibra natural de pinus (serragem) como reforço em componentes automotivos compostos de polipropileno. Master's thesis, Universidade Federal do Paraná, Curitiba, Brazil.

Wahi, R., Chua, L. A., Choong, T. S. Y., Ngaini, Z., \& Nourouzi, M. M. (2013). Oil removal from aqueous state by natural fibrous sorbent: an overview. Separation and Purification Technology, 113:51-63. DOI: 10.1016/j.seppur.2013.04.015

Wei, Q. F., Mather, R. R., Fotheringham, A. F., \& Yang, R. D. (2003). Evaluation of nonwoven polypropylene oil sorbents in marine oil-spill recovery. Marine Pollution Bulletin, 46:780-783. DOI: 10.1016/S0025-326X(03)00042-0

Wexler, P. (2005). Encyclopedia of Toxicology. 2nd ed. Cambridge, Academic Press, UK.

Wu, D., Fang, L., Qin, Y., Wu, W., Mao, C., \& Zhu, H. (2014). Oil sorbents with high sorption capacity, oil/water selectivity and reusability for oil spill cleanup. Marine Pollution Bulletin, 84:263-267. DOI: 10.1016/j.marpolbul.2014.05.005

Wu, J., Wang, N., Wang, L., Dong, H., Zhao, Y., \& Jiang, L. (2012). Electrospun porous structure fibrous film with high oil adsorption capacity. Applied Materials \& Interfaces, 4(6):3207-3212. DOI: 10.1021/am300544d

Xu, T., Wang, Y., Xu, Y., Cao, W., Liu, C., \& Shen, C. (2014). Crystallization behavior and nucleation analysis of isotactic polypropylene with a multiamide nucleating agent. Polymer Testing, 36:62-68.

Yang, S. Z., Jin, H. J., Wei, Z., He, R. X., Ji, Y. J., Li, X. M., \& Yu, S. P. (2009). Bioremediation of oil spill in cold en vironments: a review. Pedosphere, 19:371-381. DOI: 10.1016/S1002-0160(09)60128-4 